Published in final edited form as:

J Contam Hydrol. 2010 June 25; 115(1-4): 46-63. doi:10.1016/j.jconhyd.2010.03.005.

\title{
Dense, Viscous Brine Behavior in Heterogeneous Porous Medium Systems
}

\author{
D. Johnson Wright ${ }^{a}$, J.A. Pedit ${ }^{a}$, S.E. Gasda ${ }^{a}$, M.W. Farthing ${ }^{b}$, L.L. Murphyc, S.R. Knight ${ }^{d}$, \\ G.R. Brubakerd, and C.T. Millera \\ D. Johnson Wright: nomad12@email.unc.edu; J.A. Pedit: pedit@email.unc.edu; S.E. Gasda: sgasda@email.unc.edu; M.W. \\ Farthing: matthew.w.farthing@erdc.usace.army.mil; L.L. Murphy: Ilmurph@gmail.com; S.R. Knight: \\ sknight@ensr.aecom.com; G.R. Brubaker: GBrubaker@ensr.aecom.com; C.T. Miller: casey_miller@unc.edu \\ aDepartment of Environmental Sciences and Engineering, University of North Carolina, Chapel Hill,
} North Carolina 27599-7431 USA

bU.S. Army Engineer Research and Development Center, Vicksburg, Mississippi 39180-6199 USA

${ }^{\circ} \mathrm{CH} 2 \mathrm{M}$ Hill, Atlanta, Georgia 30346 USA

dAECOM, Morrisville, North Carolina 27560 USA

\begin{abstract}
The behavior of dense, viscous calcium bromide brine solutions used to remediate systems contaminated with dense nonaqueous phase liquids (DNAPLs) is considered in laboratory and field porous medium systems. The density and viscosity of brine solutions are experimentally investigated and functional forms fit over a wide range of mass fractions. A density of 1.7 times, and a corresponding viscosity of 6.3 times, that of water is obtained at a calcium bromide mass fraction of 0.53. A three-dimensional laboratory cell is used to investigate the establishment, persistence, and rate of removal of a stratified dense brine layer in a controlled system. Results from a field-scale experiment performed at the Dover National Test Site are used to investigate the ability to establish and maintain a dense brine layer as a component of a DNAPL recovery strategy, and to recover the brine at sufficiently high mass fractions to support the economical reuse of the brine. The results of both laboratory and field experiments show that a dense brine layer can be established, maintained, and recovered to a significant extent. Regions of unstable density profiles are shown to develop and persist in the field-scale experiment, which we attribute to regions of low hydraulic conductivity. The saturated-unsaturated, variable-density ground-water flow simulation code SUTRA is modified to describe the system of interest, and used to compare simulations to experimental observations and to investigate certain unobserved aspects of these complex systems. The model results show that the standard model formulation is not appropriate for capturing the behavior of sharp density gradients observed during the dense brine experiments.
\end{abstract}

\section{Keywords}

DNAPL; Remediation; Instabilities; Fingering; Modeling

(C) 2010 Elsevier B.V. All rights reserved.

Correspondence to: C.T. Miller, casey_miller@unc.edu.

Publisher's Disclaimer: This is a PDF file of an unedited manuscript that has been accepted for publication. As a service to our customers we are providing this early version of the manuscript. The manuscript will undergo copyediting, typesetting, and review of the resulting proof before it is published in its final citable form. Please note that during the production process errors may be discovered which could affect the content, and all legal disclaimers that apply to the journal pertain. 


\section{Introduction}

The effective, efficient, and economical remediation of subsurface systems contaminated with DNAPLs remains a significant environmental challenge. Over the last several years, the use of dense-brine methods have been explored as a means to control DNAPL movement during mobilization-based remediation approaches. We refer collectively to these approaches as brinebased remediation technologies (BBRT's). The basic premise behind BBRT's is that a dense brine can be used to increase the density of the aqueous phase and inhibit downward migration of DNAPL in the presence of DNAPL mobilizing flushing solutions, such as surfactants, or to induce upward mobilization of brine by increasing buoyancy forces.

An example application of BBRT's involves the establishment of a dense brine layer above a low permeability layer and beneath a DNAPL-contaminated region, lowering of the water table to increase gravity forces acting on the DNAPL to mobilize the DNAPL downward, vertical flushing with a surfactant solution to further mobilize the DNAPL downward, collection of the mobilized DNAPL from the top of the brine layer, and secondary treatment of the residual DNAPL remaining in the unsaturated zone using, for example, vapor extraction. Such an approach has proven effective in three-dimensional, heterogeneous laboratory systems (Johnson et al., 2004).

Laboratory experiments to investigate a range of BBRT's have been performed in one-, two-, and three-dimensional porous medium systems, and heterogeneous systems have been the focus of these experiments (Hill et al., 2001; Johnson et al., 2004; Miller et al., 2000).

Encouraging results have been reported based upon these experiments, including the efficient removal of high fractions of DNAPL from heterogeneous, three-dimensional systems (Hill et al., 2001; Johnson et al., 2004).

The encouraging results of laboratory investigations of BBRT's notwithstanding, many open fundamental issues must be resolved before a determination of the feasibility of using BBRT's for active source-zone remediation at the field scale can be made. One set of these open issues deals with the behavior of the dense brine solutions of which relatively little is known. For example, the viscosity of calcium bromide solutions has not been carefully measured and functionally described for a complete range of mass fractions. In addition, relatively little work has been done to understand flow and transport phenomena in porous medium systems for solutions that have the range of density and viscosity variations of interest for BBRT's. It is known that non-ideal dispersion behavior exists for other non-dilute brine systems, although the appropriate model to describe such systems is an open issue (Hassanizadeh and Leijnse, 1995; Landman et al., 2007b). As with any system that exhibits the range of density and viscosity variations characteristic of BBRT's, both gravity and viscous fingering instabilities are a potential concern depending upon displacement patterns and medium characteristics. As a result of these complexities, no mechanistic simulation model has been developed to simulate brine behavior during the application of BBRT's.

The fundamental open issues with dense brine behavior are more than intellectual curiosities if one wishes to carefully assess the practicality of BBRT's. For example, it is important to understand: the expected density of a brine layer that can be achieved, which affects the DNAPLs for which movement can be controlled; the time scale of the stability of a brine layer, which impacts methods needed to maintain the integrity of a brine barrier; the fraction of the brine that can be recovered as a function of mass fraction, which impacts economical efficiency and the potential for reuse; the rate of removal of relatively dilute brine solutions, which may not be reusable but may be required to ensure environmental compliance; and strategies and limitations for emplacing and removing brine effectively in complex systems, which will determine the number, configuration, and use schedule of injection and removal wells. 
The overall goal of this study is to investigate some of the open scientific and practical issues associated with dense, viscous brine behavior in heterogeneous porous medium systems. The specific objectives of this work include: (1) to determine the density and viscosity of calcium bromide solutions over a wide range of mass fractions; (2) to determine the feasibility of establishing and maintaining a high density layer in a heterogeneous porous medium at the laboratory scale; (3) to assess the rate of brine recovery from a heterogeneous laboratory system; (4) to assess the scalability of experimental results achieved in the laboratory to a heterogeneous field-scale system; (5) to evaluate the role of instabilities in brine layer emplacement, maintenance, and removal at the field-scale; (6) to develop a numerical simulation model to describe dense brine movement; (7) to apply the numerical model to support the understanding of laboratory and field observations; and (8) to assess remaining issues requiring resolution to achieve a mature level of understanding of dense brine behavior in heterogeneous porous medium systems.

\section{Background}

\subsection{Overview}

The dense, viscous fluids of concern in this work can exhibit complex patterns of flow and transport in porous medium systems that depend upon fluid properties, solid medium properties, and displacement patterns (Schincariol and Schwartz, 1990; Schincariol et al., 1994; Sudicky, 1986; Voss and Souza, 1987; Welty and Gelhar, 1991, 1992). While such systems are of significant recent interest due to applications that include waste disposal (Nordbotten et al., 2004; Rumynin et al., 2005), DNAPL remediation (Hill et al., 2001; Johnson et al., 2004; Miller et al., 2000), and saltwater intrusion (Abarca et al., 2007; Brovelli et al., 2007; Goswami and Clement, 2007; Held et al., 2005; Zhang et al., 2001), our understanding of such systems is not complete. In the sections that follow, we briefly summarize the state of knowledge regarding equations of state, density effects, viscous effects, porous medium property effects, model formulation, and simulators.

\subsection{Equations of State}

Fluid flow through a porous medium depends on the density and viscosity of the fluid. In systems with a wide range of variability in these properties, equations of state have to be established to effectively model the system. Although there is a lack of published data for calcium bromide, several functional forms for density, $\rho$, and dynamic viscosity, $\mu$, have been proposed for sodium chloride. The most commonly used non-dilute forms are for density (Diersch and Kolditz, 2002; Kolditz et al., 1998; Watson et al., 2002),

$$
\rho=\rho_{0} \exp (\gamma \omega)
$$

where $\rho_{0}$ is the reference density, $\gamma$ is a fitting parameter, and $\omega$ is the salt mass fraction; and for viscosity (Johannsen et al., 2006; Watson et al., 2002; Zhou et al., 2005)

$$
\mu=\mu_{0}\left(1+A \omega+B \omega^{2}+C \omega^{3}\right)
$$

where $\omega$ is the salt mass fraction and $A, B$, and $C$ are fitting parameters.

However, several other studies have used laboratory or field data to fit a range of empirical expressions for density and viscosity relations (Batzle and Wang, 1992; Gill, 1982; Kemp et al., 1989; McCain, 1991; Mercer et al., 1975; Palliser and McKibbin, 1998; Phillips et al., 1981; Rowe and Chou, 1970). These functional forms, all of which were derived for sodium chloride with the exception of Gill (1982) and McCain (1991), were compared by Adams and 
Bachu (2002). They found that several different functional forms for density and viscosity represented the available data for sodium chloride adequately for a range of conditions depending on salinity, pressure, and temperature. They also found that both density and viscosity differences between estimated values increased with increasing mass fraction with a difference in density of up to $20 \%$, and a difference in viscosity of up to $50 \%$ noted between different estimation methods at high mass fractions. Such differences suggest that care must be taken in choosing an appropriate equation of state. The density and viscosity properties of calcium bromide, and their respective equations of state, have not been reported over the wide range of mass fractions of interest for BBRT's.

\subsection{Density Effects}

Fluid densities change as a function of fluid pressures, temperatures, and chemical composition. The primary causes of density-dependent flow are due to temperature changes and compositional effects. Both of these motivating conditions have been the source of a substantial amount of recent research (Ackerer et al., 1999; Dentz et al., 2006; Diersch and Kolditz, 2002; Flowers and Hunt, 2007; Graf and Therrien, 2007; Jiao and Hötzl, 2004; Landman and Schotting, 2007; Nigam and Woods, 2006; Prasad and Simmons, 2003; Schotting et al., 1999; Simmons et al., 2001, 2002; Wood et al., 2004). When nonuniform densities exist in a porous medium system, a gravitational driving force gives rise to preferential flow of a more dense fluid overlying a less dense fluid in the vertical direction and can result in gravity fingering (Prasad and Simmons, 2003; Schincariol et al., 1994, 1997; Simmons et al., 2001; Simmons and Narayan, 1997; Welty and Gelhar, 1991; Woods and Carey, 2007). Densitydependent flow will occur until either an impermeable boundary is encountered or the fluid properties, hence density, change to remove the density gradient. In other words, such systems tend toward a stable state. For the non-isothermal case, this implies stability when an isothermal condition has been obtained, or conversely that unstable conditions and fluid motion can persist in certain cases, such as in a classical Raleigh-Bernard convection system (Gebhart et al., 1988).

For compositionally-motivated density-dependent flow, a different situation results. The thermodynamic equilibrium condition for a closed system is a solution of uniform composition and density. However, gravitational forces result in a quasi-stable distribution, which can be a relatively sharply stratified system with a thin transition region for cases in which the pore space is filled with sources of two fluids that differ substantially in density. The time scale to achieve a quasi-stable stratified configuration are in general much shorter than the time scale needed to achieve thermodynamic equilibrium typified by uniform composition, since diffusive and dispersive transport is relatively slow in such non-ideal systems.

\subsection{Viscous Effects}

The standard Darcy approximation of the momentum equation predicts that specific discharge is inversely proportional to the viscosity. The generally small change in viscosity that result from compositional changes in most systems has led to a tendency to consider viscosity constant, even in systems for which density variation are of concern (Fried, 1975; Ophori, 1998). This seems reasonable for many systems and is a convenient assumption.

Viscosity variations can be important and give rise to both interesting and complex issues. For certain compositional systems, such as the dense brines of focus in this work, viscosities can be several times that of water, which greatly exceeds the contrasts observed in typical saltwater intrusion applications. Changes in viscosity of this magnitude can significantly affect flow and transport phenomena. Viscosity variations lead to the potential to develop unstable fingering when a less viscous solution displaces a more viscous solution (Heller, 1966; Juanes and Blunt, 2006; Nagatsu et al., 2007; Paterson, 1985; Welty and Gelhar, 1991; Wooding, 1969). In 
addition, when compositional variations lead to significant changes in both density and viscosity, interactions between viscous and gravity instabilities will result (Flowers and Hunt, 2007; Jiao and Hötzl, 2004). The nature of these interactions has not been completely elucidated for dense viscous brines.

\subsection{Porous Medium Property Effects}

The effects of density gradients on groundwater flow have been widely studied in recent years, so have the effects of heterogeneity in hydraulic properties of porous media on flow and transport (Elfeki and Dekking, 2001; Juanes and Blunt, 2006; Prasad and Simmons, 2003; Scanlon et al., 2003; Schincariol, 1998; Schincariol and Schwartz, 1990; Shikaze et al., 1998; Simmons et al., 2001; Simmons and Narayan, 1997; Smith and Freeze, 1979).

Investigations of the effects of heterogeneity on density-dependent flow have demonstrated a dependence of instability onset and growth or decay on the magnitude of spatial variability in subsurface characteristics, such as hydraulic conductivity (Schincariol and Schwartz, 1990; Simmons et al., 2001).

The onset and growth of density instabilities in heterogeneous media is complex. While local perturbations in the permeability field may induce the formation and growth of instabilities, continued flow through heterogeneous media may in turn reduce growth and increase stabilization of perturbations due to mixing caused by dispersion (Schincariol and Schwartz, 1990; Schincariol et al., 1997). In addition, the existence of low permeable regions such as clay lenses can dampen instability growth and in cases where the density contrast is low stabilize perturbations (Schincariol et al., 1997). In addition, simulations conducted by Schincariol et al. (1997) suggested that low permeability regions can dampen the upward migration of freshwater. Comparatively, much less is known about systems for which both large changes in density and viscosity occur in heterogeneous systems.

\subsection{Model Formulation}

While mechanistic macroscale models based upon phase and species conservation of mass equations are well established and the standard basis for formulations involving densitydependent flow in porous medium systems (e.g., Bear and Bachmat (1991); Hassanizadeh and Gray (1979); Voss (1984); Voss and Souza (1987)), the adequacy of the closure of such models is in question. As noted above, relations for densities and viscosities as functions of mass fractions are not well established and have yet to be detailed for the calcium bromide solutions of focus in this work. Without accurate relations for such key variables, model formulations and the resultant simulations will be inaccurate as well.

In addition, high concentration brine solutions are non-ideal solutions. The significance of this observation is manifest in the failure of traditional advective-dispersive models to described the observed movement and dispersion of brine fronts. Formal averaging (Hassanizadeh and Leijnse, 1995; Schotting et al., 1999; Watson et al., 2002) and homogenization approaches (Landman et al., 2007b) have been used to advance models to describe such systems, but the appropriate model formulation is considered an open issue. Recent work by Gray and Miller (2009) has advanced a new class of models that appear promising, but these models have not yet been compared to experimental data.

Experimental observations have been made to support the non-ideal nature of dense brine porous medium systems and to provide a basis for the development of improved model formulations. High concentration brines have been shown to deviate from Fickian dispersion. Gravitational effects have been shown to have a stabilizing effect on upward displacement of brine in column studies decreasing the observed amount of dispersion relative to an ideal, dilute tracer. This phenomena results in a decrease in the length of the mixing zone (Hassanizadeh 
and Leijnse, 1995). Changes in dispersive properties have been shown to depend upon flow rates (Landman et al., 2007b; Schotting et al., 1999; Watson et al., 2002), density, viscosity, and concentration gradients (Welty and Gelhar, 1991), porous medium properties (Landman et al., 2007b; Watson et al., 2002), and the magnitude of the density contrast (Landman et al., 2007b).

\subsection{Simulators}

Several production-level finite-element- and finite-volume-based simulators have been developed to model variable-density subsurface flow and transport. These include, but are not limited to, SUTRA (Voss, 1984), FEFLOW (Diersch, 2005), TOUGH2 (Oldenburg and Pruess, 1995), FEMWATER (Lin et al., 1997), and ROCKFLOW(Kolditz et al., 2001). Nonlinear compositional effects and their interaction with heterogeneous porous media mean that analytical or semi-analytical solutions are available in only limited, highly idealized cases (van Duijn et al., 1998; Verruijt, 1968). As a result, a series of benchmark problems are typically used to evaluate model performance for some subset of the challenges associated with densitydependent flow and transport.

Available benchmarks range from stable displacements with low-density contrasts (Henry, 1964) to highly unstable free-convection problems (Elder, 1967). To be more specific, common test problems include the classical Henry saltwater intrusion problem (Henry, 1964), the HYDROCOIN salt dome problem (Konikow et al., 1997; Oldenburg and Pruess, 1995), and the low-density version of the three-dimensional salt pool problem (Oswald and Kinzelbach, 2004). Stable displacement configurations with high density-contrasts are considered in column experiments (Hassanizadeh and Leijnse, 1995; Schotting et al., 1999) as well as a highdensity saltpool experiment (Oswald and Kinzelbach, 2004). On the other hand, benchmarks like the salt lake (Simmons et al., 1999) and Elder (Elder, 1967) problems involve configurations with dense fluid overlying less dense fluid and so exhibit highly unstable fingering and solutions that are qualitatively different depending on the mesh resolution and numerical approximation (Diersch and Kolditz, 2002; Frolkovic and De Schepper, 2001).

Collectively these benchmarks highlight the particular challenges of modeling density dependent flow and transport. In addition to the basic complication of nonlinear closure relations for density and viscosity and potentially non-ideal dispersion behavior, densitydependent coupling places a premium on accurate, stable resolution of solution fronts and accurate velocity approximations (Ackerer and Younes, 2008; Diersch and Kolditz, 2002; Mazzia and Putti, 2002). For problems with gravity or viscous fingering instabilities, mesh resolution has proven critical. In comparisons among multiple simulators, a number of discrepancies have come to the forefront. Discretization effects have resulted from different mesh types and refinement levels. For the Elder problem, several researchers have found varying results on whether the central flow element is upwelling or downwelling due to changes in mesh resolution (Ackerer et al., 1999; Diersch and Kolditz, 2002; Kolditz et al., 1998; Oldenburg and Pruess, 1995; Park and Aral, 2007; Voss and Souza, 1987; Woods et al., 2003). Similar influences of mesh discretization on the speed of propagating density fingers and the number of these perturbations have been found with the salt lake problem as well (Diersch and Kolditz, 2002; Simmons et al., 1999; Wooding et al., 1997). Some have even concluded that the Elder problem is not an appropriate benchmark problem due to the influence of the boundary conditions (Simpson and Clement, 2003).

Recent efforts have been aimed at improving numerical methods to more accurately simulate the Elder problem as a benchmark (Ackerer and Younes, 2008). More broadly, unstable systems and problems with sharp interfaces continue to challenge and motivate research into improved numerical methods (Gotovac et al., 2007; Johannsen et al., 2006; Landman et al., 2007a; Younes et al., 2009). It seems clear that high-resolution simulation of dense, viscous 
fluids in complex porous medium systems remains difficult and that care is needed in applying existing simulators to such systems.

\section{Approach}

\subsection{Overview}

The work undertaken to meet the objectives of this study included characterization of solution properties, selecting and characterizing porous media, performance of three-dimensional laboratory cell experiments of brine emplacement and recovery, performance of a field-scale experiment of brine emplacement and recovery, and the modification and application of a numerical model to simulate density and viscosity dependent flow and transport phenomena in heterogeneous porous medium systems. We detail the approach used for each of these components in the subsections that follow.

\subsection{Calcium Bromide Equations of State}

Calcium bromide was chosen as the brine source because it is readily available in large quantities in a concentrated form of 53\% by weight (Synergy Fluids, Houston, Texas). In addition, the density of concentrated calcium bromide solutions can exceed the density of most DNAPLs, which allows the use of such solutions for controlling bulk DNAPL movement. This property is essential for BBRT's.

The objective of this aspect of the study was to develop equations of state for density and viscosity of high-concentration calcium bromide solutions. To do this, measurements of both properties were made for a range of mass fractions. The density of calcium bromide solutions with mass fractions up to 0.53 was measured using an Anton Paar DMA 48 density meter. The meter measures density from $0-3 \pm 0.0001 \mathrm{~g} / \mathrm{cm}^{3}$. All samples were measured at $20^{\circ} \mathrm{C}$. Viscosity was measured with a Haake Model B falling ball viscometer. All samples were measured at $20^{\circ} \mathrm{C}$ and at mass fractions that corresponded with the measured density values. Several measurements were collected for each mass fraction sample due to measurement variations. The standard deviation ranged from $0.0074 \mathrm{cP}$ at a mass fraction of zero to $0.0108 \mathrm{cP}$ at a mass fraction of 0.53 .

\subsection{Laboratory Cell Experiments}

Laboratory experiments were undertaken to meet two objectives: (1) to determine the feasibility of establishing and maintaining a high density brine layer with minimal dilution effects, and (2) to assess the rate at which brine can be removed from a system. The importance of the first objective is that the density of the brine layer that can be established determines the range of DNAPLs for which free-phase flow can be controlled. The importance of the second objective is that the brines are expensive so it is advantageous to recycle these brines, and most field-scale applications of BBRT's will require removal of a substantial fraction of the brines after remediation is accomplished. The rate and mass fractions at which these brines can be recovered bear upon the efficacy of recycling of the brine and the overall cost of such technologies. Because such aspects of these systems have not been investigated to date, it was appropriate to start with controlled laboratory studies.

Two laboratory experiments were conducted in a three-dimensional cell that measured 22.5$\mathrm{cm}$ long $\times 16.5-\mathrm{cm}$ wide $\times 24-\mathrm{cm}$ tall and was fitted with an aluminum cover. The cell was filled with porous media to a height of approximately $21 \mathrm{~cm}$. Each experiment was packed with a different medium. One experiment consisted of a quartz sand mix (QS), which was based on sieve analysis of the Dover sand (DS) and consisted of several Unimin Accusands (12/20, 20/30, 30/40, and 40/50) and two U.S. Silica sands (AFS 50/70 and F95), and was packed as a homogenized mix. The other experiment was packed as a correlated random field with DS 
collected from the Dover National Test Site (DNTS) in Dover. The properties of each porous medium are provided in Table 1.

To create a correlated random field for the DS experiment, the DS was sieved into 12 different sized fractions, all with a diameter less than $2 \mathrm{~mm}$. The DS was packed into the laboratory cell using a 21-layer heterogeneous packing based on a correlated random field model assuming anisotropic exponential covariance conditions and a log-normal particle size distribution (Christakos, 1992; Deutsch and Journel, 1992). Each layer consisted of cubes of homogeneous sands obtained from the sieved fractions of $1.5-\mathrm{cm}$ length and width and $1-\mathrm{cm}$ height. Correlation lengths of 7.5 and $5.0 \mathrm{~cm}$ for the horizontal and vertical planes, respectively, were used to match the scale of the tank used in the experiment. The mean and standard deviation of the $\log$ of particle size were $-0.789 \ln (\mathrm{mm})$ and 2.39 , respectively.

Both experiments contained a series of injection and extraction ports as well as sampling ports for monitoring in situ density during all phases of the BBRT. Stainless steel tubing (2.21-mm i.d., 3.05-mm o.d.) was used for injecting and extracting brine from locations 0.5 and $4.5 \mathrm{~cm}$ above the bottom of the cell. The layout of the port locations is represented in Figure 1. All injection and extraction ports were point sources and sinks, respectively. All boundaries of the cell were no flow boundaries, but the top of the cell was vented to the atmosphere. Ports labeled with a "B" in Figure 1 were located $4.5 \mathrm{~cm}$ from the bottom of the cell and ports labeled with a " $L$ " were located $0.5 \mathrm{~cm}$ from the bottom of the cell. Stainless steel tubing $(0.51-\mathrm{mm}$ i.d., $0.82-\mathrm{mm}$ o.d.) was used as sampling ports. The cell was packed with sand, the ports inserted, the system sealed using a gasket-lined aluminum lid, and the cell vibrated to consolidate the media. The system was flushed with $\mathrm{CO}^{2}$ gas prior to injecting de-aired deionized (DDI) water through the deepest ports to saturate the system.

The phases of the BBRT emulated in the laboratory experiments included establishing a brine barrier by injecting brine with a mass fraction of $0.53 \mathrm{~g} / \mathrm{g}\left(\rho=1.7098 \mathrm{~g} / \mathrm{cm}^{3}\right)$ near the bottom of the cell and displacing freshwater upward, pumping near the brine barrier interface as it would be done during implementation of a remedial strategy, dewatering of the cell and bulk brine removal, and flushing of the residual brine remaining with freshwater to reduce in situ densities and the total dissolved solids (TDS) concentrations. Table 2 provides a summary of injection and extraction locations, pore volumes (PV), as well as sampling locations during each stage of the implemented BBRT. Effluent and in situ density samples were collected and analyzed during the entire process.

For the QS experiment, fluid was extracted through an upper port (E1) until air was present in the effluent. Fluid extraction was continued through the lower ports (L1-L4), again until air was present in the effluent. The system was partially refilled with DDI water through the lower ports until the medium surrounding the upper ports appeared to be fully saturated. The system was then flushed by injecting DDI water into the lowest ports on one side of the tank (L3-L4) and extracting from the lowest ports on the other side (L1-L2). Additional flushing was conducted by injecting DDI water into the upper ports (B1-B6) and extracting from the lower ports (L1-L4).

Brine was injected into the lowest ports of the DS cell to minimize mixing due to density inversions and establish the brine layer more efficiently. Once the brine layer was established, the calcium bromide was recovered initially by extracting fluid through E1, E2, B3, and B4 during the pumping and the initial dewatering stage. Then, fluid was extracted through the lower ports (L1-L4) and the system partially refilled and flushed from side to side.

A volume fraction of less than 0.005 of tetrachloroethylene was injected into the DS cell. This low volume fraction of organic liquid was confined to the upper portions of the cell and was 
assumed to have a negligible effect on the brine aspects of this work, which is the focus of this work.

\subsection{Field Experiment}

A field-scale experiment was performed at the Dover National Test Site (DNTS) to assess the scalability of experimental results achieved in the laboratory to a heterogeneous field-scale system. Of special interest was an assessment of the brine barrier density that could be achieved and maintained, and the nature of brine mass recovery as a function of mass fraction. While tetrachlorethylene was injected in the field study, this aspect of the work is not a focus of this manuscript. Because the volume fraction of tetrachlorethylene injected was less than 0.005 , it had a negligible effect on the brine aspects of the study.

The DNTS site consists of a water table aquifer overlying an extensive clay formation. The permeable sands extend from the ground surface to a depth of 11- to 14-m below ground surface (bgs) and are comprised of fine to medium sands with occasional discontinuous clay and silt lenses (ARA Inc., 1996). The ambient water table is approximately 8- to 11-m bgs, giving a saturated thickness of the water table aquifer of about $3 \mathrm{~m}$. The vertically averaged hydraulic conductivity of the aquifer is $2.6 \mathrm{~m} / \mathrm{day}$. Organic matter, soluble salts, and clay contents of the aquifer are low. The clay formation consists of gray, firm, dense marine clays and is approximately 6-m thick with a hydraulic conductivity of $2.6 \times 10^{-3} \mathrm{~m} /$ day (ARA Inc., 1996).

Test Cell 3 was used in this study and was enclosed using double-walled W275 Waterloo Barrier ${ }^{\mathrm{TM}}$ Sheet Piles driven into the subsurface and keyed into a confining aquitard approximately 14-m bgs. Test Cell 3 was equipped with injection/extraction wells, multilevel micro-samplers (MLS), and contaminant injection points. The layout of these locations is displayed in Figure 2. The test cell area was covered to prevent precipitation from infiltrating into the cell. The cell was $4.6 \mathrm{~m} \times 3 \mathrm{~m}$ in the horizontal plane. The average depth to the clay layer was approximately $12.3-\mathrm{m}$ bgs with the highest clay elevation at $11.7-\mathrm{m}$ bgs. The elevation of the top of the clay layer was irregular as is shown in Figure 3, adding complications to both the physical experiment and computer simulations. Previous studies in this cell included a cosolvent tracer study (Brooks et al., 2002), a cosolvent solubilization study (Brooks et al., 2004), a surfactant solubilization study (Childs et al., 2006), and a cyclodextrin solubilization study (Tick et al., 2003).

A calcium bromide solution was injected into the test cell using two injection phases to establish a brine barrier at approximately $11.6-\mathrm{m}$ bgs. The brine barrier interface (BBI) is terminology used to represent the region in which a transition from a relatively dilute solution to a concentrated brine solution occurs; the BBI varied in location in response to injection and withdrawal. The intended design location for the BBI was $0.9 \mathrm{~m}$ above the average clay layer elevation and $0.3 \mathrm{~m}$ above the highest clay elevation.

The establishment of the brine barrier was divided into two phases using a series of screened wells that had been packed off and relying on the clay layer and sides of the cell as no flow boundaries to control flow of brine. Brine was primarily injected below 11.58-m bgs into the center of the test cell during Phase 1. Brine was injected at the same depth but on the left and right sides of the test cell during Phase 2. Details of the set up of each stage is summarized in Table 3, which contains information on the location of injection and extraction wells during brine barrier establishment. Phase 1 of the field study involved injecting brine into four locations to concentrate brine into the center, deeper part of the cell. Wells 45, 46, 55, and 56 (refer to Figure 2 for well locations) were chosen for Phase 1. Brine was injected into the bottom of these wells, which were packed off at 11.4-m bgs. Packing off the wells forced brine into the deepest portions of the cell, which promoted a stable displacement of freshwater upward 
and limited brine mixing and dilution, which would decrease the efficiency of brine injection. The displaced water was then removed using wells $41,42,44,51,53$, and 54 by placing pumps at approximately $10.3-\mathrm{m}$ bgs. The water table at the beginning of brine injection was located at $9.3-\mathrm{m} \mathrm{bgs.}$

After injecting approximately 2,440 $\mathrm{L}$ of brine over nine days during Phase 1, the brine injection/water extraction locations were reversed such that brine was injected below 11.4-m bgs into wells $41,42,44,51,53$, and 54 and displaced fluids were removed at $10.3-\mathrm{m}$ bgs from wells 45, 46, 55, and 56. This switch to Phase 2 of the brine injection strategy allowed the perimeter of the cell to fill with brine and provided time for relaxation of hydraulic mounds formed around Phase 1 injection wells. Phase 2 continued until another $6,440 \mathrm{~L}$ of brine was injected, which occurred over a period of 27 days. During both brine injection phases, and the rest of the study, the fluid density was monitored in situ using multilevel samplers, through effluent sampling from wells, and through periodic bailing of wells. These data assisted in understanding how the brine propagated through the system, as well as determining the temporal profile of brine recovery.

Once the brine barrier was adequately established, brine continued to be injected to maintain the brine barrier in the cell. Brine injection was accomplished using the Phase 2 injection wells, however these wells were simultaneously pumped by packing off locations above the BBI. To minimize brine loss, packers were installed below the pumped portion of the well screens to prevent excess brine depletion. During this 48 -day period, approximately $4,000 \mathrm{~L}$ of brine was injected to maintain the brine barrier.

At the end of the injection period, pumps were lowered to the bottom of the wells to remove bulk brine. To achieve an efficient removal of fluids, pumps were relocated to more productive wells when fluid recoveries from wells diminished due to low water levels. The remainder of the study was devoted to flushing the residual brine by adding freshwater to the system. Based on density measurements from the multilevel samplers, pumps and freshwater injection locations were rotated to target high fluid density regions.

\subsection{Modeling Approach}

Our intent with the modeling was to determine if the brine recovery process could be simulated to mimic the laboratory experiment and to use the model to evaluate the effects of density and viscosity variations and heterogeneity of the intrinsic permeability at the field scale. Another purpose of the simulations, although not discussed herein, was to assist the execution of the field experiment by running preliminary and real-time simulations to guide the brine injection and removal design that was implemented. Because of the difficulty of modeling dense brine behavior, we view the simulation work as preliminary in nature.

We chose SUTRA, a simulator distributed by the United States Geological Survey, to carry out these objectives. SUTRA can be used to simulate saturated or unsaturated densitydependent groundwater flow and transport in three-dimensional systems. It uses a hybrid finiteelement mesh discretization and an implicit, first-order, finite-difference time-stepping method to approximate the conservation equations (Voss and Provost, 2002). There is a user option of solving either (1) the conservation of mass of a fluid and mass of a solute or (2) the conservation of mass and energy of a fluid, where the first option was chosen in this study. The code solves for fluid pressures and solute mass fractions as they change with time. As is true with all discretization-based groundwater modeling applications, the method is approximate in nature and the accuracy depends upon the spatial and temporal discretization, error tolerances of the solvers, and accuracy of the parameter estimates. An additional consideration for these simulations is that, as noted before, the appropriate mathematical model formulation for such systems is considered an open issue. For all of these reasons, our expectation was that SUTRA 
was an approximate tool that we relied upon to give a semi-quantitative indication of fluid flow and species transport.

An assumption made in developing the SUTRA simulator is that solute concentrations do not affect viscosity. The equation of state for density in SUTRA is also of a form that does not match the dense brines of concern in this work. Therefore, modified equations of state for density and viscosity that accurately described concentrated calcium bromide solutions were implemented in the modified SUTRA simulator. The functional form of these equations is discussed later.

A further modification to the SUTRA source code involved altering extraction specifications. This change was essential for the brine recovery simulations. The SUTRA model requires a mass rate of input or removal for any external source or sink. However, in the field-scale experiment, volumetric injection and extraction rates were used to control the level of the water table in the test cell. Because the mass recovery rate from a well varied with time, it was not convenient to convert a desired volume extraction rate to a mass extraction rate necessary for SUTRA input.

Source code modifications were made such that a volume extraction rate could be specified in the simulation. To make this change, the mass fraction output at each time step in SUTRA, $\omega^{\mathrm{t}}$, and the density equation of state were utilized. From a given volumetric extraction rate $\left(E_{V}\right)$, the mass extraction rate required by SUTRA at each time step $\left(E_{m}^{t}\right)$, was approximated by:

$$
E_{m}^{t}=E_{V}\left[\rho^{t-1} \omega^{t-1}\right]
$$

Because the time steps were relatively small compared to the time rate of change of the density, this approach provided an accurate approximation for the desired mass extraction rate. This change allowed the amount of fluid in the system to be easily controlled in the simulator to match the field conditions.

A laboratory system and a field-scale system were simulated. Some of the relevant model parameters used in the SUTRA simulations for both the laboratory and field-scale simulations are given in Table 4.

The laboratory simulation was designed to mimic the laboratory experiment that contained a homogenized mix of quartz sand. Location of injection, extraction, and sampling ports were selected based upon the corresponding locations in the experiment. Initial conditions used in the simulation correspond to the sharp concentration gradient observed in the experiment once the dense brine layer had been established. The initial mass in place in the simulation was approximately $750 \mathrm{~g}$ of calcium bromide. Hydrostatic pressure was set to zero at the top of the domain. The simulation included system dewatering, partial refilling with freshwater, and both horizontal and vertical flushing to remove the residual brine.

Because of the non-ideal dispersion behavior of dense brines, the effect of different dispersivity coefficients was explored for this system. Three sets of longitudinal and transverse dispersivity coefficients were tested, as shown in Table 5, with the range varying over three orders of magnitude. The dilute tracer longitudinal dispersivity for this system was estimated to be on the order of $0.1 \mathrm{~cm}$.

Field-scale laboratory simulations were designed to represent the DNTS test cell during the brine emplacement period. The elevation of the top of an irregularly shaped clay layer was 
interpolated based on well installation data. The locations of wells and sampling points were based on their locations within the test cell. Minimal information on the heterogeneity of the domain was available, so as a first approximation we assumed that the effects of heterogeneity could be evaluated by treating permeabil-ity as a log-normally distributed spatial random field (SRF)(Freeze, 1975; Simmons et al., 2001). Realizations of three-dimensional permeability fields were generated using sequential Gaussian simulation (SGSIM)(Deutsch and Journel, 1992). It was assumed that changes in permeability were gradual and that the domain could be approximated by a Gaussian covariance model. Correlation length scales could not be determined because of a lack of permeability data. The vertical and horizontal correlation length scales $\left(\gamma_{\mathrm{y}}\right.$ and $\gamma_{\mathrm{x}}$, respectively) were assumed to be $0.5 \mathrm{~m}$ and $2.5 \mathrm{~m}$, respectively. SGSIM was used to create two permeability fields: a domain heterogeneous in three dimensions, and a vertically layered domain with each layer having a homogeneous permeability. In the latter case, SGSIM was used to generate a packing with a desired vertical correlation length and vertical covariance structure. Information on permeability fields used in each brine simulations are available in Table 6.

Initial conditions for the DNTS cell simulations consisted of a solute mass fraction set to zero, and a hydrostatic pressure profile with the top of the water table equal to zero. All boundaries where set as no flow boundaries, which matched the physical system that was contained with sheet piling. Brine was injected into the model system below $11.58-\mathrm{m}$ bgs based on the strategy implemented in the field study such that Phase 1 occurred at an average injection rate of $5.34 \times 10^{-3} \mathrm{~kg} / \mathrm{s}$ over a 9-day period and Phase 2 occurred at an average injection rate of $4.75 \times 10^{-3} \mathrm{~kg} / \mathrm{s}$ over a 27 -day period. Fluids were extracted from the top of the domain over the 36-day period at an average rate of $2.95 \times 10^{-6} \mathrm{~m}^{3} / \mathrm{s}$.

\section{Results}

\subsection{Equations of State}

We measured the density and viscosity of calcium bromide solutions as a function of mass fraction yielding the results shown in Figure 4. Both relationships exhibited nonlinear behavior that was not well described by standard equations of state. The change of viscosity for calcium bromide was substantial, therefore such changes must be accounted for to model transport phenomena accurately in the systems of concern in this work and for BBRT's in general.

An empirical equation of state for fluid density as a function of calcium bromide mass fraction was estimated from the data using nonlinear least-squares analysis. The third-degree polynomial that accurately describes the measured data is

$$
\rho(\omega)=0.8319 \omega^{3}+0.4958 \omega^{2}+0.8417 \omega+0.9982
$$

where density is given in $\mathrm{g} / \mathrm{mL}$, and 0.9982 is the reference density.

An empirical equation of state for fluid viscosity as a function of calcium bromide mass fraction was estimated from the data and is of the form

$$
\mu(\omega)=1.0019 \mathrm{e}^{\left[16.43 \omega^{3}-5.190 \omega^{2}+1.552 \omega\right]}
$$

where viscosity is given in $\mathrm{cP}$.

Using Eq. 1 for the density relationship with a $\gamma$ value of 0.6923 , a value that was originally derived from sodium chloride solution data, would lead to an under prediction of the density 
of a calcium bromide solution. Estimating the fitting parameter from the calcium bromide data yields a $\gamma$ value of 0.9855 and improves the model fit for Eq. 1. However, the improved relationship over and under predicts density when the mass fraction is less than and greater than 0.4 , respectively. The viscosity relationship typically used to model groundwater systems (Eq. 2), which was fitted to the calcium bromide data such that $\mathrm{A}=1.43, \mathrm{~B}=-6.77$, and $\mathrm{C}=27.98$, under predicts viscosity for mass fractions greater than 0.42 relative to the data and the empirically derived Eq. 5 .

\subsection{Laboratory Study}

4.2.1 Laboratory Cell Experiment Results-In situ density samples were collected at elevations from 2.0 to $7.0 \mathrm{~cm}$ from the bottom of the tank during the QS experiment. Figure 5 shows density as a function of depth and number of pore volumes of brine injected during the establishment of the brine barrier. At early times, sampling locations in close proximity to injection ports had the highest density measurements. This led to large variations in density at a given elevation as can be seen in the data collected after injecting $0.23 \mathrm{PV}$ of brine. For example, the density ranged from $1.01-1.52 \mathrm{~g} / \mathrm{cm}^{3}$ at an elevation of $3.0 \mathrm{~cm}$. Density variations at a given elevation greatly diminished after the addition of $0.40 \mathrm{PV}$ of brine. After $0.40 \mathrm{PV}$, observed densities from the bottom of the tank to the extraction port at $4.5 \mathrm{~cm}$ (i.e., the designated BBI) exceeded the density of trichloroethylene (TCE), which has a density of 1.46 $\mathrm{g} / \mathrm{cm}^{3}$. After $0.57 \mathrm{PV}$, observed brine densities from the bottom of the tank to the extraction port at $4.5 \mathrm{~cm}$ exceeded the $1.62 \mathrm{~g} / \mathrm{cm}^{3}$, which corresponds to the density of one of the denser DNAPLs of interest, tetrachloroethylene (PCE).

Density sampling during the DS experiment was limited compared to sampling during the QS experiment. Samples were only collected at elevations from 1.0 to $3.0 \mathrm{~cm}$ from the bottom of the tank. Density as a function of depth after the establishment of the brine barrier are shown in Figure 6. Markers in this figure represent the average brine density and lines represent the range of observed densities. There was little variation in density in the lower portion of the cell after the addition of $0.42 \mathrm{PV}$ of brine.

After establishing a brine barrier, pumping began at the BBI, as it would during implementation of a BBRT. During pumping, brine continued to be injected into the cell through the deepest ports to maintain the brine barrier and counter losses due to pumping. Pumping induced mixing around the extraction wells. Therefore, in situ densities were measured to determine the effect of pumping in the vicinity of the BBI. Densities measured near the end of pumping are shown in Figure 6 for the DS medium. After significant pumping from an elevation of $4.5 \mathrm{~cm}$, densities measured at an elevation of $3.0 \mathrm{~cm}$ ranged from 1.3 to $1.7 \mathrm{~g} / \mathrm{cm}^{3}$. The lowest densities were observed near the extraction locations. The average density in the brine barrier increased and the variability decreased closer to the bottom of the cell. The results suggests that capillary forces will need to offset the loss of buoyancy to prevent DNAPLs with densities similar to TCE and PCE from migrating below the extraction elevation, particularly near the extraction points.

In an effort to recover the calcium bromide from the QS experiment, the cell was partially drained, partially refilled, and then flushed with DDI water. In situ densities were measured during various stages of brine recovery and the results are shown in Figure 7. Dewatering the cell resulted in densities ranging from $1.14 \mathrm{~g} / \mathrm{cm}^{3}$ at an elevation of $7 \mathrm{~cm}$ to $1.67 \mathrm{~g} / \mathrm{cm}^{3}$ near the bottom. The DDI water injected to partially resaturate the cell mixed with the residual brine and resulted in a lower vertical density gradient with densities ranging from $1.22 \mathrm{~g} / \mathrm{cm}^{3}$ at an elevation of $7 \mathrm{~cm}$ to $1.45 \mathrm{~g} / \mathrm{cm}^{3}$ near the bottom. Flushing with less than two pore volumes of DDI water reduced density to less than $1.00 \mathrm{~g} / \mathrm{cm}^{3}$ throughout the cell. 
Although reducing in situ density is important, the ability to reduce the TDS of the effluent stream is equally important in terms of waste treatment and restoration of the system to its original state. The TDS of the effluent stream are shown in Figure 8. The Secondary Drinking Water Standard for TDS is $500 \mathrm{mg} / \mathrm{L}$ (U.S. EPA, 2009). In the experiment using the QS medium, we achieved a TDS concentration of $789 \mathrm{mg} / \mathrm{L}$ after flushing approximately $2.5 \mathrm{PV}$ of DDI water through the portion of the cell originally containing the brine barrier. The QS experiment exhibited a log-linear decrease in TDS with cumulative flushing volume. The experiment using the DS medium also exhibited this log-linear nature, but with slight deviations due to changes in flow rates during flushing. The TDS in the effluent samples from the DS experiment were less than $300 \mathrm{mg} / \mathrm{L}$ after flushing with 3.3 pore volumes. Flushing was performed throughout the cell in the DS study whereas flushing was limited to the lower half of the cell in the QS study. In addition, the majority of the flushing in the QS study consisted of flushing from the upper ports to the lower ports while flushing in the DS study consisted of flushing between lower ports. As a result of the differences in flushing strategy and media heterogeneity, less freshwater was needed to reduce the TDS effluent concentrations in the DS study than the QS experiment. Flushing of approximately 3.3 PVs of freshwater after draining the DS medium resulted in recovery of approximately $98.9 \%$ of the injected brine from the DS medium. The mass fraction of $91 \%$ of the recovered brine exceeded 0.1 , which is the approximate limit for recycling brines economically after reconcentration.

4.2.2 Model Results-The modified SUTRA simulator, which accounts for density and viscosity as functions of calcium bromide mass fraction using Eqs. 4 and 5, was used to simulate the brine recovery process of the QS laboratory experiment. To evaluate the model results, the concentration data in Figure 8 were converted to fraction of mass removed and compared with the simulated data.

Examination of Figure 9 shows that all three simulations with different values of dispersivity (T1, T2, and T3) overestimate mass removal for the first 0.2 pore volumes removed, but then diverge from each other as they progress to the end. As expected, the simulation with the highest dispersivity values (T1) leads to excessive dispersion and dilution of the dense brine layer that results in significant underprediction of overall mass removal. The simulation with dispersivity values closest to dispersivity for a dilute system (T2) shows good agreement with the experimental data until approximately 1 pore volume flushed, but then begins to underpredict mass removal for the remainder of the simulated period. The final simulation (T3) with the lowest dispersivity values shows overprediction for much of the simulation, however by the end, the total mass removal is less than the experimental value by an order of magnitude.

The simulated results indicate that the model is only adequate in predicting accurate mass removal rates at the very beginning of the flushing period. However, the differences in slope after 1.5 pore volumes flushed suggests that dispersion is an issue. As the simulations progress, the model is not able to maintain a sharp density gradient in the vertical and the dense brine layer becomes diluted, thus hampering effective mass removal. This observation is confirmed by the model result of vertical density profile not shown here. Even with an arbitrarily low dispersivity, the mass removal does not match the overall experimental data.

Numerical diffusion in the model results is controlled to the extent possible using a converged grid. However, some of the poor match to the laboratory data can be attributed to numerical diffusion that cannot be completely eliminated, due to the methods employed in the simulator. Despite the presence of some numerical effects, the model results also suggest that the SUTRA model formulation of dispersion, which assumes a dilute system and Fickian dispersion, is not appropriate for modeling high-concentration brines with non-ideal dispersive behavior. Further work is needed to develop appropriate simulators for these types of non-dilute systems. 


\subsection{Field Study}

4.3.1 Field Experiment Results-Density samples collected from the multilevel samplers were used to investigate the spatial and temporal distribution of brine within the test cell. In addition, samples were also collected from the effluent stream to maintain a mass balance of the brine during each stage of the BBRT including brine barrier establishment, pumping and dewatering, bulk brine removal, and flushing of the residual brine. There was considerable variation in density at all depths at the end of Phase 1 as is shown in Figure 10. Densities were greatest near the injection wells and decreased with distance from the injection wells. Phase 2 resulted in an increase in density in regions that were low in density at the conclusion of Phase 1. Density variation at all depths decreased by the end of Phase 2 .

Density measurements during and at the end of Phase 2 indicted that there were regions in the lower portion of the cell where density inversion developed. The localized regions where apparent instabilities persisted were between wells 42 and 44 and between wells 51 and 53 . These results suggest there was some heterogeneity effect that lead to a density inversion in these areas. Utilization of extraction wells in the vicinity of these regions did not occur during the pumping and dewatering stage. However, wells were used as extraction wells in regions where sufficient brine had been injected to achieve the required density to impede the vertical movement of PCE. Selection of wells away from the unstable regions decreased the possibility of brine barrier deterioration due to mixing induced by pumping in the unstable regions.

To minimize the development of instabilities, extraction pumps were initially placed above the proposed BBI and slowly lowered during the course of pumping until the extraction pumps were at the level of the BBI. This strategy decreased brine losses, reduced mixing at the BBI, and promoted continued stabilization of the brine barrier. After removing 0.68 pore volumes -with a pore volume being based on the maximum saturated zone extending from the clay layer to $8.5-\mathrm{m}$ bgs and yielding an approximate fluid volume of $16,200 \mathrm{~L}$ of fluid-from the test cell, densities below the BBI were essentially unchanged compared to densities at the end of Phase 2 as shown in Figure 11. The average brine density and range of densities within the brine barrier held relatively constant during vertical flushing of the upper portion of the cell. The observed densities over a several month period showed that the brine barrier was a stable feature that could be maintained. Densities above the brine barrier decreased as fluid was flushed downward towards the extraction locations. The large range of densities that existed above the BBI suggest that all areas were not uniformly flushed, resulting in the persistence of localized high concentrations of brine above the BBI.

After partial dewatering of the test cell, multilevel sampler data revealed results similar to laboratory observations in that densities in the brine barrier zone were still relatively high (i.e., exceeded $1.3 \mathrm{~g} / \mathrm{cm}^{3}$ ). Residual brine from the brine establishment phase that had been bypassed during the flushing stage contributed to elevated density readings in the upper regions of the domain, but, in general, densities decreased with elevation above the BBI.

Samples collected after refilling the cell with water indicated that densities above 12.0-m bgs ranged from 1.01 to $1.32 \mathrm{~g} / \mathrm{cm}^{3}$ with the results shown in Figure 12. Below 12.0-m bgs, the density increased with depth with the exception of the local regions of lower density observed earlier. The test cell was undisturbed for three months after the completion of the primary study. Density samples collected at the end of this period indicated that the wide variation in density at a given depth observed earlier diminished and that the overall vertical density gradient also diminished. Apparent density instabilities in the lower portion of the cell persisted, but were less pronounced. The reductions in variability and vertical gradient were due to diffusion and small-scale flow driven by local density instabilities. Drainage from above the water table increased the water level in the cell by $0.63 \mathrm{~m}$ during the three month period and the drainage, depending on its density, may have also impacted the density profile. 
Effluent samples collected throughout the study revealed changes in the composition of the effluent stream depending on the stage of the BBRT as shown in Figure 13. As brine was injected into the system during establishment of the brine barrier, the thickness of the barrier increased and brine migrated upward toward the extraction elevation leading to an increase in the density of the effluent stream. The extraction pumps were lowered during the addition of the flushing solution which resulted in an initial increase in the density of the effluent stream, followed by a slight decline. Further lowering of the extraction pumps during dewatering and bulk brine removal resulted in an increase in the effluent density from 1.3 to $1.6 \mathrm{~g} / \mathrm{cm}^{3}$. A 0.4 PV flush with water resulted in a decrease in the density of the effluent to $1.1 \mathrm{~g} / \mathrm{cm}^{3}$.

The overall process recovered $92 \%$ of the calcium bromide injected into the system. The number of pore volumes of water flushed through the field-scale system was only a small fraction of the pore volumes that were flushed through the laboratory systems. In addition the rate of flushing was higher in the test cell than in the laboratory systems. Laboratory systems were refilled at a slow rate to try to re-saturate the cell. Further flushing could have removed additional calcium bromide mass as in the laboratory experiments, but time constraints did not make further flushing possible.

It may be possible to recycle brine during the application of a BBRT if the contaminants can be removed and the brine reconcentrated. We may assume that the cost of such a recycling process would be inversely related to the calcium bromide mass fraction of the effluent. Assessing the potential for economic brine recycling includes examining the volume of brine effluent that exceeds a minimal mass fraction $\left(\omega_{\min }\right)$ that is defined as the mass fraction below which the cost of recycling becomes uneconomical. Figure 14 shows that, for example, if $\omega_{\min }=0.25$ than more than $50 \%$ of the effluent that was collected could be recycled economically. Similarly, if $\omega_{\min }=0.10$, then more than $88 \%$ of the collected effluent could be feasibly recycled. The exact mass fraction at which it becomes uneconomical to reconcentrate the brine would likely be project-dependent.

4.3.2 Model Results-Field-scale simulations were also conducted to investigate the formation of a density inversion (or instability) during the injection of brine to form the brine barrier. Since minimal information was available on the porous media properties, three permeability fields were used in the simulations: a homogeneous field, a field based on a Gaussian covariance model, and a layered permeability field (see Table 6). The areallyaveraged results of the simulations are shown in Figure 15. The completion of Phase 1, which corresponds to brine injection into the center 4 wells and deeper zone of the test cell (see Figure 3 ), shows a stable and relatively sharp density profile in the simulations with homogeneous and Gaussian permeability fields. However, the simulation with the layered permeability field developed a density inversion early in this phase. Inspection of the permeability field in the instability region for the layered system indicates that the permeability decreases by more than two orders of magnitude between 12-m bgs and the bottom of the domain (see Figure 15). The low permeability inhibited the migration of brine into this region.

Density instabilities were found to develop in each of the simulated systems by the end of Phase 2. The inversion that developed during Phase 1 for the layered permeability system persisted through Phase 2. In addition, the simulations for the homogeneous and Gaussian permeability fields also developed slight density inversions beneath $12-\mathrm{m}$ bgs, although not as pronounced as the layered permeability field system. The initiation and persistence of the density inversion during this phase for the homogeneous and Gaussian cases is largely due to the location of the Phase 2 injection wells, which were along the outer edges of the cell where the topography of the bottom surface becomes shallower (Figure 3 ). In addition, Phase 2 injection was three times as long as Phase 1, which resulted in most of the total calcium bromide mass being injected in shallower zones. This also caused circulation of fresh water into the deeper zones, diluting the 
dense brine injected during Phase 1 . Thus, stable density gradients existed locally but at different elevations, and therefore the apparent density inversion in Figure 15 is an artifact of averaging. Additional simulations showed that after the system equilibrates for a number of days, the brine migrates slowly into the deeper zones for the simulations with homogeneous and Gaussian permeability fields, and the apparent density instability in Figure 15 for these two cases stabilized. The density instability for the layered permeability field persisted as expected due to the strong permeability contrast in the deeper region.

Compared with the field-scale experiment observations shown in Figure 11, the simulated results with the layered permeability field best approximates the observed average density gradient at the end of Phase 2. This indicates that a low permeability zone likely exists along the top of the clay layer as discussed earlier. Near the top of the observed BBI between -10.8 and $-11.8 \mathrm{~m}$ (bgs), the simulated results show a density gradient not as sharp as observed in the test cell and with lower average concentrations. Despite the use of a converged grid, this is likely due to numerical dispersion, and the underlying assumption of Fickian diffusion. These results further reveal the overall inadequacy of the simulator to maintain sharp density gradients over time as observed in both the laboratory and field experiments.

\section{Discussion}

Knowledge of the fluid properties of a high-concentration calcium bromide solution is essential for understanding the dynamics of a BBRT based upon such a solution. This was of particular importance because the density was 1.7 times and the viscosity was 6 times that of water at the mass fraction used in the BBRT studies. Changes in the density and viscosity over the range of mass fractions experienced during implementation of a BBRT can result in a $72 \%$ decrease in hydraulic conductivity.

Although laboratory studies conducted to date have implemented brine barrier strategies, the properties of such brine barriers have not been investigated. We monitored in situ brine densities during all stages of a BBRT implementation. Laboratory studies showed effective establishment of dense brine barriers that achieved densities in excess of a variety of chlorinated solvents. These densities were maintained with some localized reductions in density near extraction wells. With adequate brine barrier thickness, localized reductions in density due to mixing near extraction wells should not affect the effectiveness of a brine barrier at arresting downward migration of most DNAPLs.

With adequate flushing, more than $98 \%$ of the injected brine was recovered from the laboratory systems. High recoveries are needed if in situ calcium bromide concentrations are going to be substantially reduced. The ability to reduce calcium bromide concentrations is particularly important in natural systems that may eventually serve as sources for drinking water.

Some of the primary differences between the laboratory and field studies, other than the domain size, were the degree of heterogeneity, the source and sink type (i.e. the laboratory experiments had point sources and sinks while the field experiment had line sources and sinks), and the presence of residual fluids from previous studies in the field test cell. Obstacles that arose during brine injection and maintenance in the field setting included brine mounding around wells and density instabilities within the medium, which were investigated in more detail using a modified SUTRA simulator. Any remnants remaining from the prior studies had a minimal effect on density and viscosity in comparison to the brine solution since initial measurements were found to be comparable to water. A more likely influence of the remnants would be pore clogging as the solutions serve as food for bacteria, which would inhibit brine migration in such areas if it occurred. 
Hydraulic issues were encountered during the dewatering and bulk brine removal phase of the field-scale study. We were unable to achieve the degree of dewatering of the brine barrier that we had achieved in the laboratory systems, which made removal of the residual brine more difficult. Based on its areal extent and porosity, the test cell had approximately $4,850 \mathrm{~L}$ of pore space volume per meter of depth. Lowering the water table resulted in the fluid recovery of water that corresponded to approximately a third of the pore space volume per thickness of medium. This inefficient fluid recovery was partly due to the slow drainage of the unsaturated zone relative to the time frame of the field experiment. Reductions in the thickness of the saturated zone diminished the efficiency of the bladder pumps used in the wells, which also contributed to the inefficient fluid recovery. Although reductions in fluid recovery occurred, we were able to recover a high fraction of the injected brine and expect that with further freshwater flushing additional mass removal was feasible.

We modified SUTRA to include the density and viscosity relationships for calcium bromide. SUTRA's mass-based extraction scheme was converted to a volume-based extraction scheme, which made simulating BBRT's easier. There was general agreement between the SUTRA simulation and effluent measurements from the laboratory system during the early period of brine-barrier flushing. However, excessive numerical dispersion, even for very low dispersivity values, led to excessive mixing and poor brine recovery in the latter part of the simulation.

SUTRA simulations also provided insight to field-scale observations including the role of density- and viscosity-dependent flow, and the interaction of the two properties during brine barrier flushing.

Density inversions were observed in the field study as well as in simulations of the field study. Simulated density instabilities were found near areas of low permeability, which were found in the deeper portions of the system. Density instabilities may have arose from decreased permeability because such conditions existed in the deeper portions of the test cell that were in close proximity to the clay layer. These instabilities persisted in both the field and simulated studies further suggesting their existence was due to areas of low permeability. The formation of localized density inversions in low permeability regions may not pose a problem with respect to the performance of BBRT's. If the permeability is low enough to limit migration of brine, the low permeability regions are likely not accessible to a DNAPL either, at least prior to a DNAPL coming into contact with a solution that promotes mobilization.

The ability to accurately monitor and predict in situ densities in a field setting is difficult. Fluids in wells stratify quickly relative to fluids in the adjoining medium so monitoring density in wells can be unreliable, particularly when density inversions exist in the medium. Discrete interval sampling within wells or multilevel samplers can be used to alleviate density sampling difficulties.Model simulations can be used to describe the density within a brine barrier, but modeling requires detailed knowledge of the porous medium properties, particularly if it is hoped that the model will capture localized inversions. A conservative brine barrier strategy would be to increase the thickness of the barrier to ensure control of mobilized DNAPL, but such an approach may lead to significant amounts of DNAPL trapped below the brine barrier interface where recovery would be difficult.

Although we have gained insight into the behavior and application of brine barriers, we believe there are still a number of relevant issues that should be considered to mature our understanding. These issues include the following items:

1. Model Development and Simulators. Density-dependent models and simulators are still an active area of research. As the theory, model, and numerics continue to develop, so will a more mature scientific understanding of the systems of concern, the role of sharp fronts, and density and viscosity induced instabilities. 
2. Behavior in the Absence of Hydraulic Controls. Installation of sheet piles may be unrealistic at some sites so wells must be used to control brine migration. Well placement would have to be optimized to minimize migration and loss of brine outside of the contaminated region. Such systems would require larger volumes of brine, which emphasizes the importance of being able to recycle and reuse brine on site.

3. Horizontal Flushing of Remedial Fluids. The impact of horizontal flushing with remedial fluids, such as surfactants and cosolvents, on brine barrier stability has not been investigated. Horizontal flushing is more common than vertical flushing, but it may increase mixing at the brine barrier interface. The impact of such a flushing strategy on brine barrier maintenance needs some consideration.

4. Barrier Thickness. We observed persistent density inversions during the field experiment. Consequently, the brine barrier thickness in some locations was less than the desired thickness. The minimal thickness of a brine barrier needed to control mobilization needs to be assessed. It is expected that this thickness will be a function of distance from an extraction or injection well, flow rates, density difference between the brine and the DNAPL, and the DNAPL and medium properties.

5. Clay Effects. Due to the length of time a brine barrier may overlay a clay layer, it is important to determine the impact of brine on the structural integrity of the clay layer. In addition, the rate of loss of brine into the underlying clay layer needs to be investigated. Diffusion of brine back out of the clay layer after removal of the bulk brine is also a concern as it could pose a long-term source of dissolved salt into the aquifer.

We believe that resolution of these issues will require substantial work, but such a resolution would benefit future applications of BBRT's.

\section{Conclusions}

We characterized and defined the relationship of the density and viscosity of calcium bromide solutions over a range of mass fractions that were observed during implementation of a BBRT. Commonly used approaches for representing these relationships were unable to adequately describe our data over the entire mass fraction range. Therefore, we developed equations of state to better represent the relationships between density and viscosity as a function of calcium bromide mass fraction.

We observed changes in the density within a brine barrier as a function of space and time while establishing and maintaining a brine barrier in laboratory cells. We found that a brine barrier could be effectively established by injecting about 0.4 pore volumes of brine into the confined cell. The brine barrier could also be maintained during the course of a BBRT experiment.

It is feasible to recover high percentages of brine at the end of a BBRT. In the laboratory setting we were able to recover more than $98 \%$ of the injected brine, of which more than $90 \%$ had a mass fraction exceeding 0.1 , which is the lower limit at which it is economically viable to reconcentrate and recycle the effluent. Focusing flushing on the lower portion of the laboratory cell, or primarily the region where the brine barrier existed, is more efficient in reducing calcium bromide concentrations than flushing the entire cell. Freshwater flushing of the brine barrier region was found to require less than half of the pore volumes of freshwater needed to reduce the calcium bromide concentration to a similar level when flushing the entire system.

A BBRT was implemented at the field-scale. We were able to successfully establish and maintain a brine barrier, and recover approximately $92 \%$ of the injected brine. Instabilities were encountered in the field due to the complex heterogeneities that existed near an underlying 
clay layer. These instabilities were persistent through the course of the study. We do not believe the instabilities posed a major problem because they existed in locations that were not likely to be easily penetrated by mobilized DNAPL.

\section{Acknowledgments}

This work was supported by National Institute of Environmental Health Sciences Grant P42 ES05948, AECOM, and the Dead Sea Bromine Group. The Dover National Environmental Technology Test Site is established and managed by the Strategic Environmental Research and Development Program. The demonstration complied with prescribed NETTS protocols and guidelines for quality assurance, health and safety, technical completeness, and regulatory compliance. The support of the NETTS facilities and test location manager and staff are gratefully acknowledged.

\section{References}

Abarca E, Carrera J, Sanchez-Vila X, Dentz M. Anisotropic dispersive Henry problem. Advances in Water Resources 2007;30(4):913-926.

Ackerer P, Younes A. Efficient approximations for the simulation of density driven flow in porous media. Advances in Water Resources 2008;31(1):15-27.

Ackerer P, Younes A, Mose R. Modeling variable density flow and solute transport in porous medium I. Numerical model and verification. Transport in Porous Media 1999;35:345-373.

Adams JJ, Bachu S. Equations of state for basin geofluids: Algorithm review and intercomparison for brines. Geofluids 2002;2(4):257-271.

ARA Inc. Tech. rep. Prepared by Applied Research Associates, Inc. for Armstrong Laboratory; 1996. Groundwater remediation field laboratory - GRFL: Hydrogeology characterization and site development. volume I: Site characterization and development.

Batzle M, Wang ZJ. Seismic properties of pore fluids. Geophysics 1992;57(11):1396-1408.

Bear, J.; Bachmat, Y. Introduction to Modeling of Transport Phenomena in Porous Media. Dordrecht, The Netherlands: Kluwer Academic Publishers; 1991.

Brooks MC, Annable MD, Rao PSC, Hatfield K, Jawitz JW, Wise WR, Wood AL, Enfield CG. Controlled release, blind tests of DNAPL characterization using partitioning tracers. Journal of Contaminant Hydrology 2002;59(3-4):187-210. [PubMed: 12487413]

Brooks MC, Annable MD, Rao PSC, Hatfield K, Jawitz JW, Wise WR, Wood AL, Enfield CG. Controlled release, blind test of DNAPL remediation by ethanol flushing. Journal of Contaminant Hydrology 2004;69(3-4):281-297. [PubMed: 15028395]

Brovelli A, Mao X, Barry DA. Numerical modeling of tidal influence on density-dependent contaminant transport. Water Resources Research 2007;43

Childs J, Acosta E, Annable MD, Brooks MC, Enfield CG, Harwell JH, Hasegawa M, Knox RC, Rao PSC, Sabatini DA, Shiau B, Szekeres E, Wood AL. Field demonstration of surfactant-enhanced solubilization of DNAPL at Dover Air Force Base, Delaware. Journal of Contaminant Hydrology 2006;82(1-2):1-22. [PubMed: 16233935]

Christakos, G. Random Field Models in the Earth Sciences. San Diego, CA: Academic Press; 1992.

Dentz M, Tartakovsky DM, Abarca E, Guadagnini A, Sanchez-Vila X, Carrera J. Variable-density flow in porous media. Journal of Fluid Mechanics 2006;561:209-235.

Deutsch, CV.; Journel, AG. GSLIB: Geostatistical Software Library and User's Guide. New York: Oxford University Press; 1992.

Diersch, H-JG. Tech. rep. Berlin, Germany: WASY GmbH; 2005. FEFLOW finite element subsurface flow \& transport simulation system reference manual.

Diersch HJG, Kolditz O. Variable-density flow and transport in porous media: Approaches and challenges. Advances in Water Resources 2002;25(8-12):899-944.

Elder JW. Transient convection in a porous medium. Journal of Fluid Mechanics 1967;27:609-623.

Elfeki A, Dekking M. A Markov chain model for subsurface characterization: Theory and applications. Mathematical Geology 2001;33(5):569-589.

Flowers TC, Hunt JR. Viscous and gravitational contributions to mixing during vertical brine transport in water-saturated porous media. Water Resources Research 2007;43(1) 
Freeze RA. A stochastic-conceptual analysis of one-dimensional groundwater flow in nonuniform homogeneous media. Water Resources Research 1975;11(5):725-741.

Fried, JJ. Groundwater pollution. In: Fried, JJ., editor. The Experimental Determination of Groundwater Pollution Parameters. Amsterdam: Elsevier Scientific Publishing Co.; 1975. p. 59-113.

Frolkovic P, De Schepper H. Numerical modelling of convection dominated transport coupled with density driven flow in porous media. Advances in Water Resources 2001;24(1):63-72.

Gebhart, B.; Jaluria, Y.; Mahajan, R.; Sammakia, B. Buoyancy Induced Flows And Transport. New York: Hemisphere; 1988.

Gill, AE. Atmosphere-ocean dynamics. New York: Academic Press; 1982.

Goswami RR, Clement TP. Laboratory-scale investigation of saltwater intrusion dynamics. Water Resources Research 2007;43(4)

Gotovac H, Andricevic R, Gotovac B. Multi-resolution adaptive modeling of groundwater flow and transport problems. Advances in Water Resources 2007;30(5):1105-1126.

Graf T, Therrien R. Variable-density groundwater flow and solute transport in irregular 2D fracture networks. Advances in Water Resources 2007;30(3):455-468.

Gray WG, Miller CT. Thermodynamically constrained averaging theory approach for modeling flow and transport phenomena in porous medium systems: 5. Single-fluid-phase transport. Advances in Water Resources 2009;32(5):681-711.

Hassanizadeh SM, Gray WG. General conservation equations for multiphase systems: 1. Averaging procedure. Advances in Water Resources 1979;2(3):131-144.

Hassanizadeh SM, Leijnse A. A non linear theory of high-concentration-gradient dispersion in porous media. Advances in Water Resources 1995;18(4):203-215.

Held R, Attinger S, Kinzelbach W. Homogenization and effective parameters for the henry problem in heterogeneous formations. Water Resources Research 2005;41(11)

Heller JP. Onset of instatbility patterns between miscible fluids in porous media. Journal of Applied Physics 1966;37(4):1566-1579.

Henry, HR. Tech. rep. U.S. Geological Survey; 1964. Effects of dispersion on salt encroachment in coastal aquifers.

Hill EH, Moutier M, Alfaro J, Miller CT. Remediation of DNAPL pools using dense-brine barrier strategies. Environmental Science \& Technology 2001;35(14):3031-3039. [PubMed: 11478259]

Jiao CY, Hötzl H. An experimental study of miscible displacements in porous media with variation of fluid density and viscosity. Transport in Porous Media 2004;54(2):125-144.

Johannsen K, Oswald S, Held R, Kinzelbach W. Numerical simulation of three-dimensional saltwaterfreshwater fingering instabilities observed in a porous medium. Advances in Water Resources 2006;29(11):1690-1704.

Johnson DN, Pedit JA, Miller CT. Efficient, near-complete removal of DNAPL from three-dimensional, heterogeneous porous media using a novel combination of treatment technologies. Environmental Science \& Technology 2004;38(19):5149-5156. [PubMed: 15506211]

Juanes R, Blunt MJ. Analytical solutions to multiphase first-contact miscible models with viscous fingering. Transport in Porous Media 2006;64(3):339-373.

Kemp NP, Thomas DC, Atkinson G, Atkinson BL. Density modeling for brines as a function of composition, temperature, and pressure. SPE Production Engineering 1989;4:394-400.

Kolditz, O.; Habbar, A.; Kaiser, R.; Rother, T.; Thorenz, C.; M; K; Moenickes, S. Tech. rep. Hannover, Germany: Institute of Fluid Mechanics and Computer Applications in Civil Engineering, University of Hannover; 2001. ROCKFLOW numerical modeling of fluid flow, mass and heat transport in subsurface systems, version 3.5.

Kolditz O, Ratke R, Diersch HJG, Zielke W. Coupled groundwater flow and transport: 1. Verification of variable density flow and transport models. Advances in Water Resources 1998;21(1):27-46.

Konikow LF, Sanford WE, Campbell PJ. Constant-concentration boundary condition: Lessons from the HYDROCOIN varible-density groundwater bench-mark problem. Water Resources Research 1997;33(10):2253-2261.

Landman AJ, Johannsen K, Schotting R. Density-dependent dispersion in heterogeneous porous media Part I: A numerical study. Advances in Water Resources 2007a;30(12):2467-2480. 
Landman AJ, Schotting R, Egorov A, Demidov D. Density-dependent dispersion in heterogeneous porous media Part II: Comparison with nonlinear models. Advances in Water Resources 2007b;30(12): 2481-2498.

Landman AJ, Schotting RJ. Heat and brine transport in porous media: the Oberbeck-Boussinesq approximation revisited. Transport in Porous Media 2007;70(3):355-373.

Lin, H-CJ.; Richards, DR.; Yeh, G-T.; Cheng, J-R.; Cheng, H-P. Tech. rep. Vicksburg, MS: U.S. Army Corps of Engineers Waterways Experiment Station; 1997. FEMWA-TER: A three-dimensional finite element computer model for simulating density-dependent flow and transport in variably saturated media.

Mazzia A, Putti M. Mixed-finite element and finite volume discretization for heavy brine simulations in groundwater. Jounal of Computational and Applied Mathematics 2002;147:191-213.

McCain JW. Reservoir fluid property correlations- state of the art. SPE Production Engineering 1991;6:266-272.

Mercer JW, Pinder GF, Donaldson IG. Galerkin-finite element analysis of hydrothermal system at Wairakei, New Zealand. Journal of Geophysical Research 1975;80(17):2608-2621.

Miller CT, Hill EH, Moutier M. Remediation of DNAPL-contaminated subsurface systems using densitymotivated mobilization. Environmental Science \& Technology 2000;34(4):719-724.

Nagatsu Y, Matsuda K, Kato Y, Tada Y. Experimental study on miscible viscous fingering involving viscosity changes induced by variations in chemical species concentrations due to chemical reactions. Journal of Fluid Mechanics 2007;571:475-493.

Nigam MS, Woods AW. The influence of buoyancy contrasts on miscible source-sink flows in a porous medium with thermal inertia. Journal of Fluid Mechanics 2006;549:253-271.

Nordbotten JM, Celia MA, Bachu S. Analytical solutions for leakage rates through abandoned wells. Water Resources Research 2004;40(4)

Oldenburg CM, Pruess K. Dispersive transport dynamics in a strongly coupled groundwater brine flow system. Water Resources Research 1995;31(2):289-302.

Ophori DU. The significance of viscosity in density-dependent flow of ground-water. Journal of Hydrology 1998;204(1-4):261-270.

Oswald SE, Kinzelbach W. Three-dimensional physical benchmark experiments to test variable-density flow models. Journal of Hydrology 2004;290(1-2):22-42.

Palliser C, McKibbin R. A model for deep geothermal brines, ii: Thermodynamic properties - density. Transport in Porous Media 1998;33(1-2):129-154.

Park CH, Aral MM. Sensitivity of the solution of the Elder problem to density, velocity and numerical perturbations. Journal of Contaminant Hydrology 2007;92(1-2):33-47. [PubMed: 17222477]

Paterson L. Fingering with miscible fluids in a Hele Shaw cell. Journal of Chemical Engineering Data 1985;28(1):26-30.

Phillips, SL.; Igbene, A.; Fair, JA.; Ozbek, H.; Tavana, M. Tech. rep. Lawrence Berkeley Laboratory Report; 1981. A technical data-book for geothermal energy utilization.

Prasad A, Simmons CT. Unstable density-driven flow in heterogeneous porous media: A stochastic study of the Elder [1967b] "short heater" problem. Water Resources Research 2003;39(1):1-21.

Rowe AM, Chou JCS. Pressure-volume-temperature-concentration relation of aqueous $\mathrm{NaCl}$ solutions. Journal of Chemical Engineering Data 1970;15:61-66.

Rumynin VG, Konosavsky PK, Hoehn E. Experimental and modeling study of adsorption-desorption processes with application to a deep-well injection radioactive waste disposal site. Journal of Contaminant Hydrology 2005;76(1-2):19-46. [PubMed: 15588572]

Scanlon BR, Mace RE, Barrett ME, Smith B. Can we simulate regional groundwater flow in a karst system using equivalent porous media models? Case study, Barton Springs Edwards aquifer, USA. Journal of Hydrology 2003;276(1-4):137-158.

Schincariol RA. Dispersive mixing dynamics of dense miscible plumes: natural perturbation initiation by local-scale heterogeneities. Journal of Contaminant Hydrology 1998;34(3):247-271.

Schincariol RA, Schwartz FW. An experimental investigation of variable density flow and mixing in homogeneous and heterogeneous media. Water Resources Research 1990;26(10):2317-2329. 
Schincariol RA, Schwartz FW, Mendoza CA. On the generation of instabilities in variable density flow. Water Resources Research 1994;30(4):913-927.

Schincariol RA, Schwartz FW, Mendoza CA. Instabilities in variable density flows: Stability and sensitivity analyses for homogeneous and heterogeneous media. Water Resources Research 1997;33 (1):31-41.

Schotting RJ, Moser H, Hassanizadeh SM. High-concentration-gradient dispersion in porous media: Experiments, analysis and approximations. Advances in Water Resources 1999;22(7):665-680.

Shikaze SG, Sudicky EA, Schwartz FW. Density-dependent solute transport in discretely-fractured geologic media: is prediction possible? Journal of Contaminant Hydrology 1998;34(3):273-291.

Simmons CT, Fenstemaker TR, Sharp JM. Variable-density groundwater flow and solute transport in heterogeneous porous media: approaches, resolutions and future challenges. Journal of Contaminant Hydrology 2001;52(1-4):245-275. [PubMed: 11695743]

Simmons CT, Narayan KA. Mixed convection processes below a saline disposal basin. Journal of Hydrology 1997;194(1-4):263-285.

Simmons CT, Narayan KA, Wooding RA. On a test case for density-dependent groundwater flow and solute transport models: The salt lake problem. Water Resources Research 1999;35(12):3607-3620.

Simmons CT, Pierini ML, Hutson JL. Laboratory investigation of variable-density flow and solute transport in unsaturated-saturated porous media. Transport in Porous Media 2002;47(2):215-244.

Simpson MJ, Clement TP. Theoretical analysis of the worthiness of Henry and Elder problems as benchmarks of density-dependent groundwater flow models. Advances in Water Resources 2003;26 (1):17-31.

Smith L, Freeze RA. Stochastic analysis of steady state groundwater flow in a bounded domain: 1. Onedimensional simulations. Water Resources Research 1979;15(3):521-528.

Sudicky EA. A natural gradient experiment on solute transport in a sand aquifer: Spatial variability of hydraulic conductivity and its role in the dispersion process. Water Resources Research 1986;22(13): 2069-2082.

Tick GR, Lourenso F, Wood AL, Brusseau ML. Pilot-scale demonstration of cyclodextrin as a solubilityenhancement agent for remediation of a tetrachloroethene-contaminated aquifer. Environmental Science \& Technology 2003;37(24):5829-5834. [PubMed: 14717202]

U.S. EPA. MCL — National Primary Drinking Water Regulations. Washington, D.C: EPA; 2009. 816F-09-0004

van Duijn CJ, Peletier LA, Schotting RJ. Brine transport in porous media:self-similar solutions. Advances in Water Resources 1998;22(3):285-297.

Verruijt A. A note on the Ghyben-Herzberg formula. Bulletin of the International Association of Scientific Hydrology 1968;XIII(4):43-46.

Voss, CI. Tech. rep. U.S. Geological Survey Water-Resources Investigations Report 84-4369, U.S. Geological Survey; 1984. A finite-element simulation model for saturated-unsaturated, fluid-densitydependent ground-water flow with energy transport or chemically-reactive single-species solute transport.

Voss, CI.; Provost, AM. Tech. rep. Reston, VA: U.S. Geological Survey; 2002. SUTRA- a model for saturated, variable-density ground-water flow with solute or energy transport.

Voss CI, Souza WR. Variable density flow and solute transport simulation of regional aquifers containing a narrow freshwater-saltwater transition zone. Water Resources Research 1987;23(10):1851-1866.

Watson SJ, Barry DA, Schotting RJ, Hassanizadeh SM. Validation of classical density-dependent solute transport theory for stable, high-concentration-gradient brine displacements in coarse and medium sands. Advances in Water Resources 2002;25(6):611-635.

Welty C, Gelhar LW. Stochastic analysis of the effects of fluid density and viscosity variability on macrodispersion in heterogeneous porous media. Water Resources Research 1991;27(8):2061-2075.

Welty C, Gelhar LW. Simulation of large-scale transport of variable density and viscosity fluids using a stochastic mean model. Water Resources Research 1992;28(3):815-827.

Wood M, Simmons CT, Hutson JL. A breakthrough curve analysis of unstable density-driven flow and transport in homogeneous porous media. Water Resources Research 2004;40(3) 
Wooding RA. Growth of fingers at an unstable diffusing interface in a porous medium or Hele-Shaw cell. Journal of Fluid Mechanics 1969;39:477-495.

Wooding RA, Tyler SW, White I, Anderson PA. Convection in ground-water below an evaporating salt lake .2. evolution of fingers or plumes. Water Resources Research 1997;33(6):1219-1228.

Woods JA, Carey GF. Upwelling and downwelling behavior in the Elder-Voss-Souza benchmark. Water Resources Research 2007;43(12)

Woods JA, Teubner MD, Simmons CT, Narayan KA. Numerical error in groundwater flow and solute transport simulation. Water Resources Research 2003;39(6)

Younes A, Fahs M, Ahmed S. Solving density driven flow problems with efficient spatial discretizations and higher-order time integration methods. Advances in Water Resources 2009;32(3):303-486.

Zhang Q, Volker RE, Lockington DA. Influence of seaward boundary condition on contaminant transport in unconfined coastal aquifers. Journal of Contaminant Hydrology 2001;49(3-4):201-215. [PubMed: 11411397]

Zhou QL, Bear J, Bensabat J. Saltwater upconing and decay beneath a well pumping above an interface zone. Transport in Porous Media 2005;61(3):337-363. 

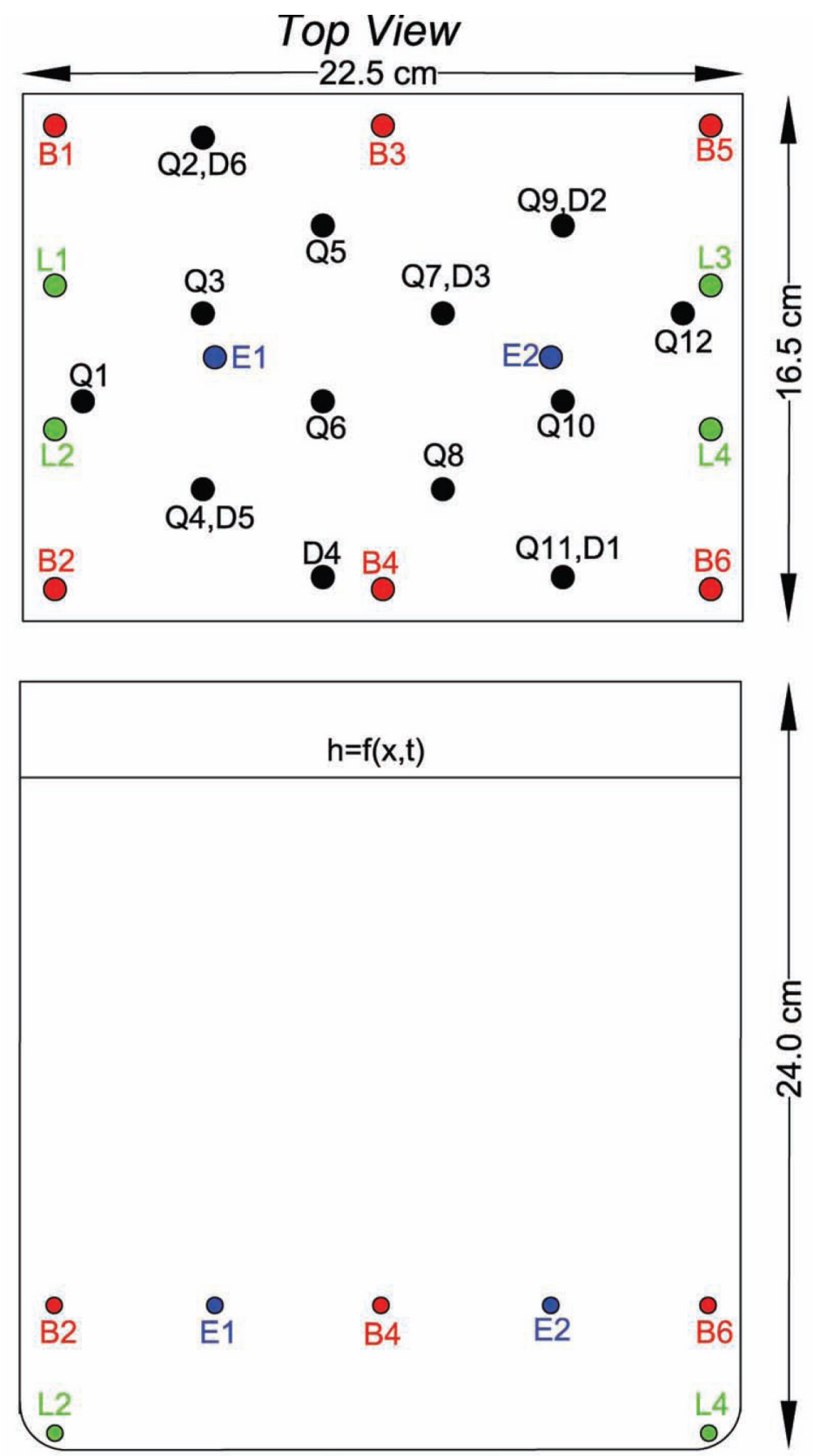

Side View

Fig. 1.

Top and side view layout of brine injection and extraction ports for the three-dimensional laboratory cell. 




Fig. 2.

Dover Test Cell 3 layout. 

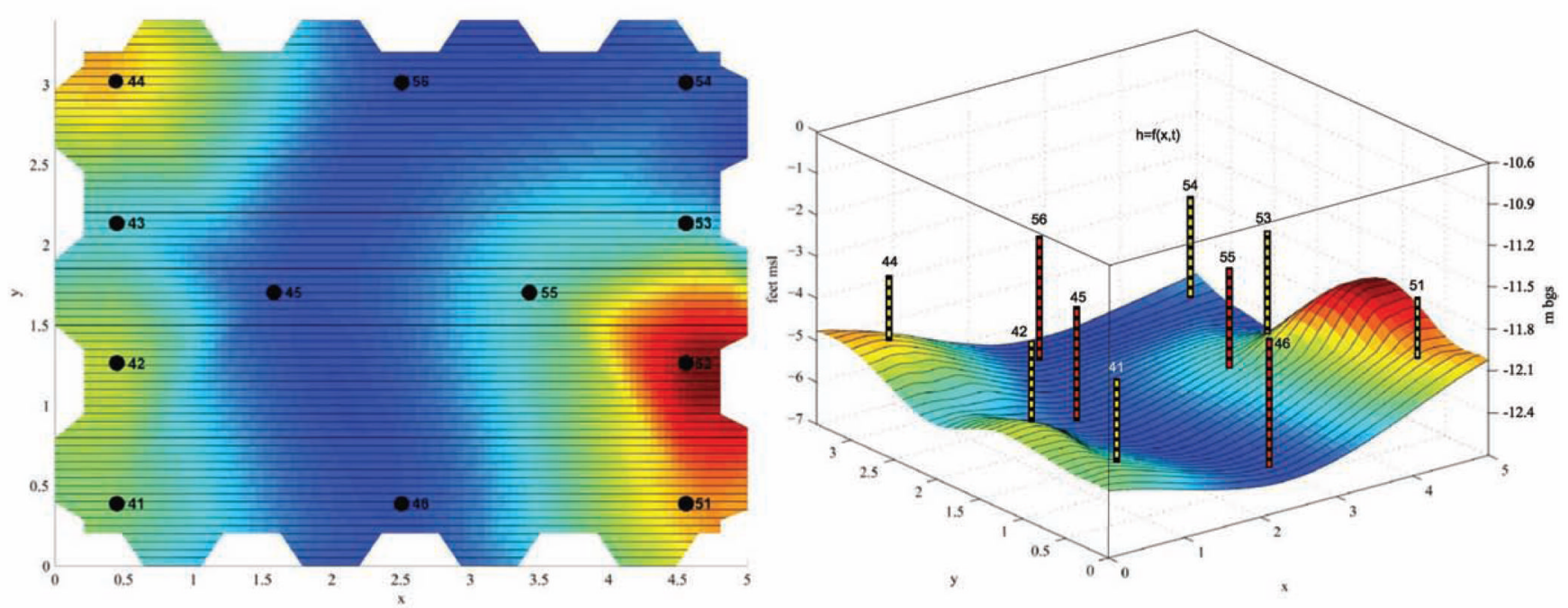

Fig. 3.

Geometry of the confining clay layer beneath Test Cell 3 and line sources for brine injection, where red locations represent Phase 1 and yellow locations Phase 2 injections. 

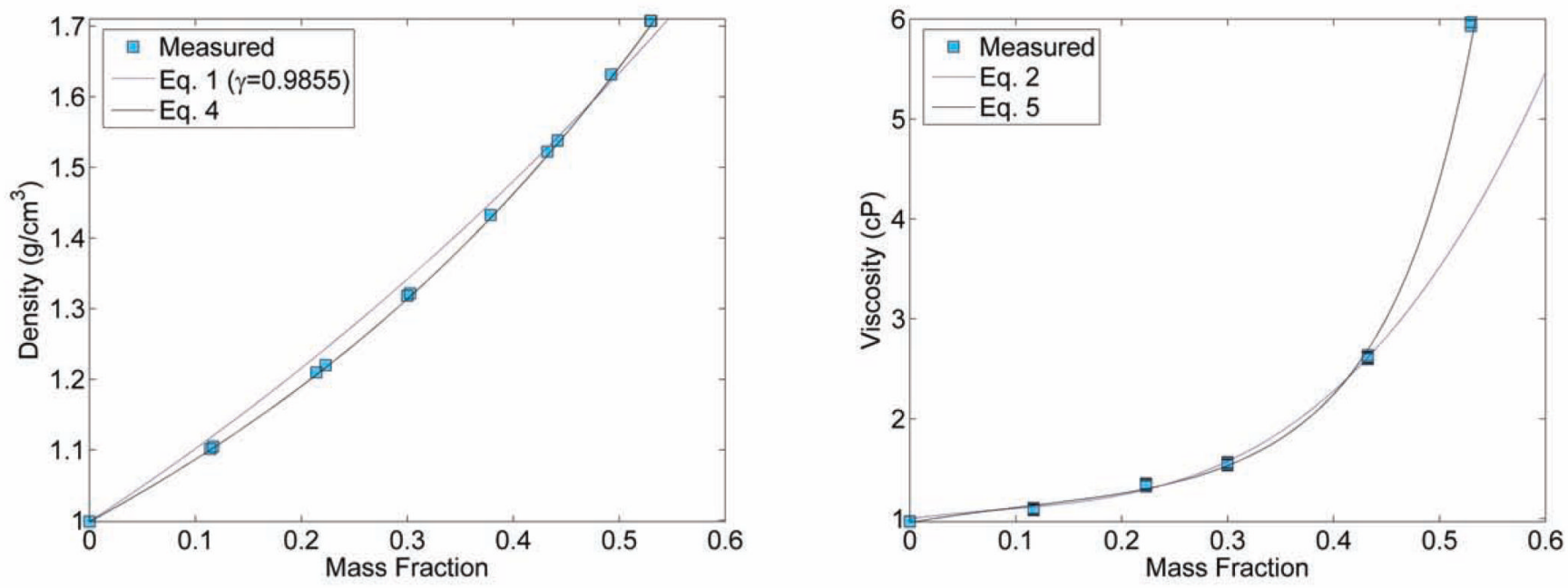

Fig. 4.

Density (left) and viscosity (right) of calcium bromide as a function of mass fraction. 


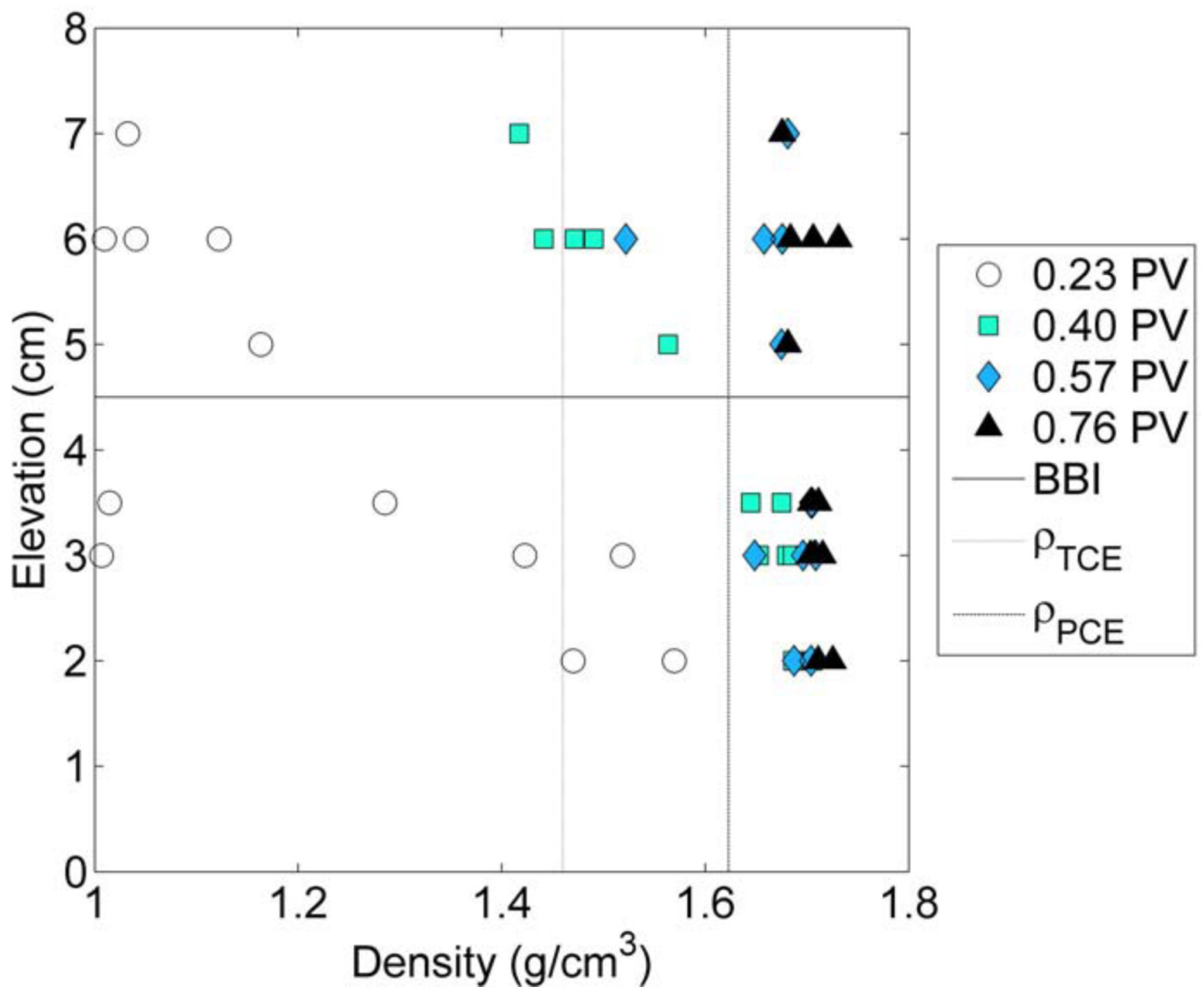

Fig. 5.

Density as a function of elevation during the establishment of the brine barrier for the QS laboratory experiment. 


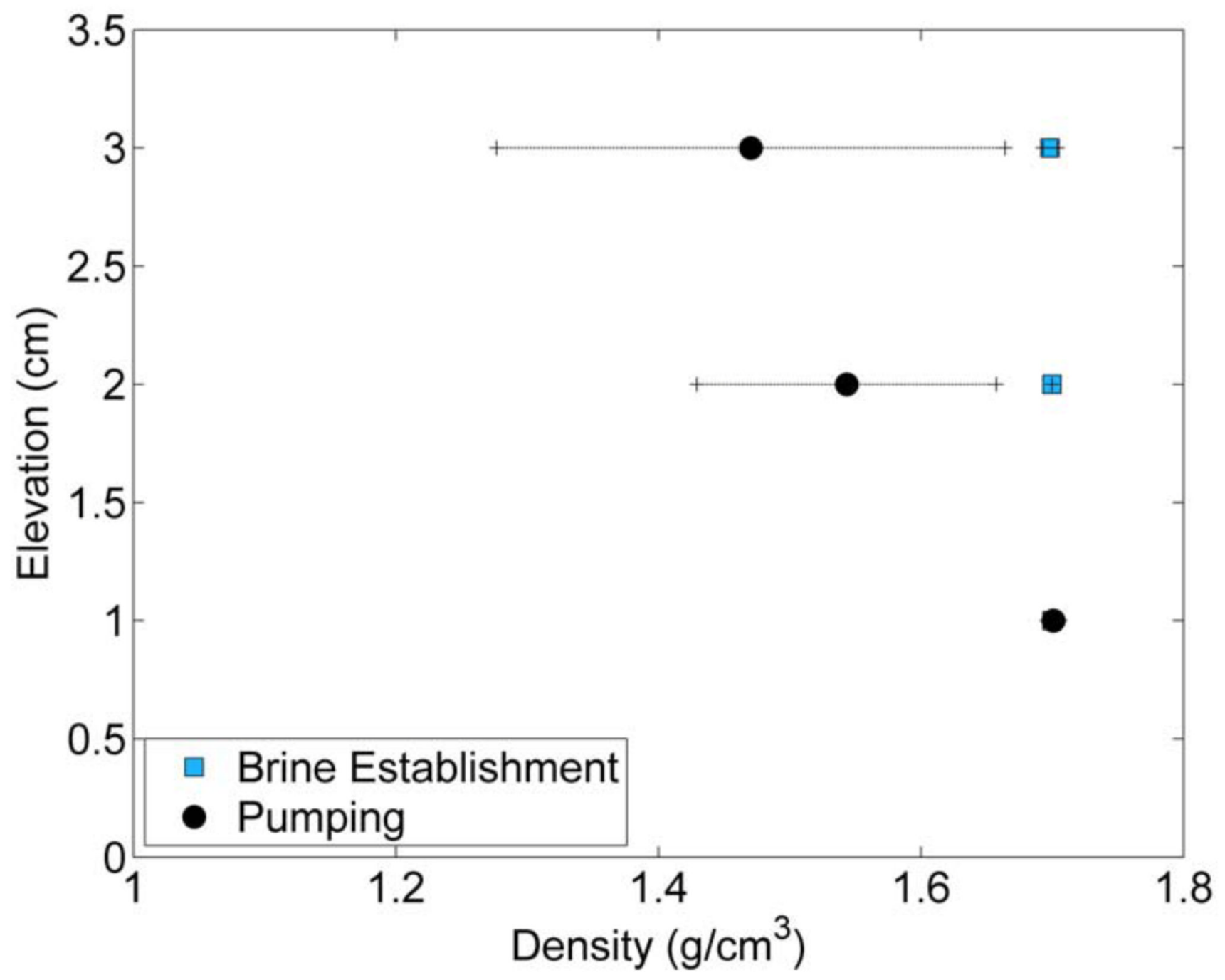

Fig. 6 .

Average density as a function of elevation after the establishment of the brine barrier and during pumping for the DS laboratory experiment. 


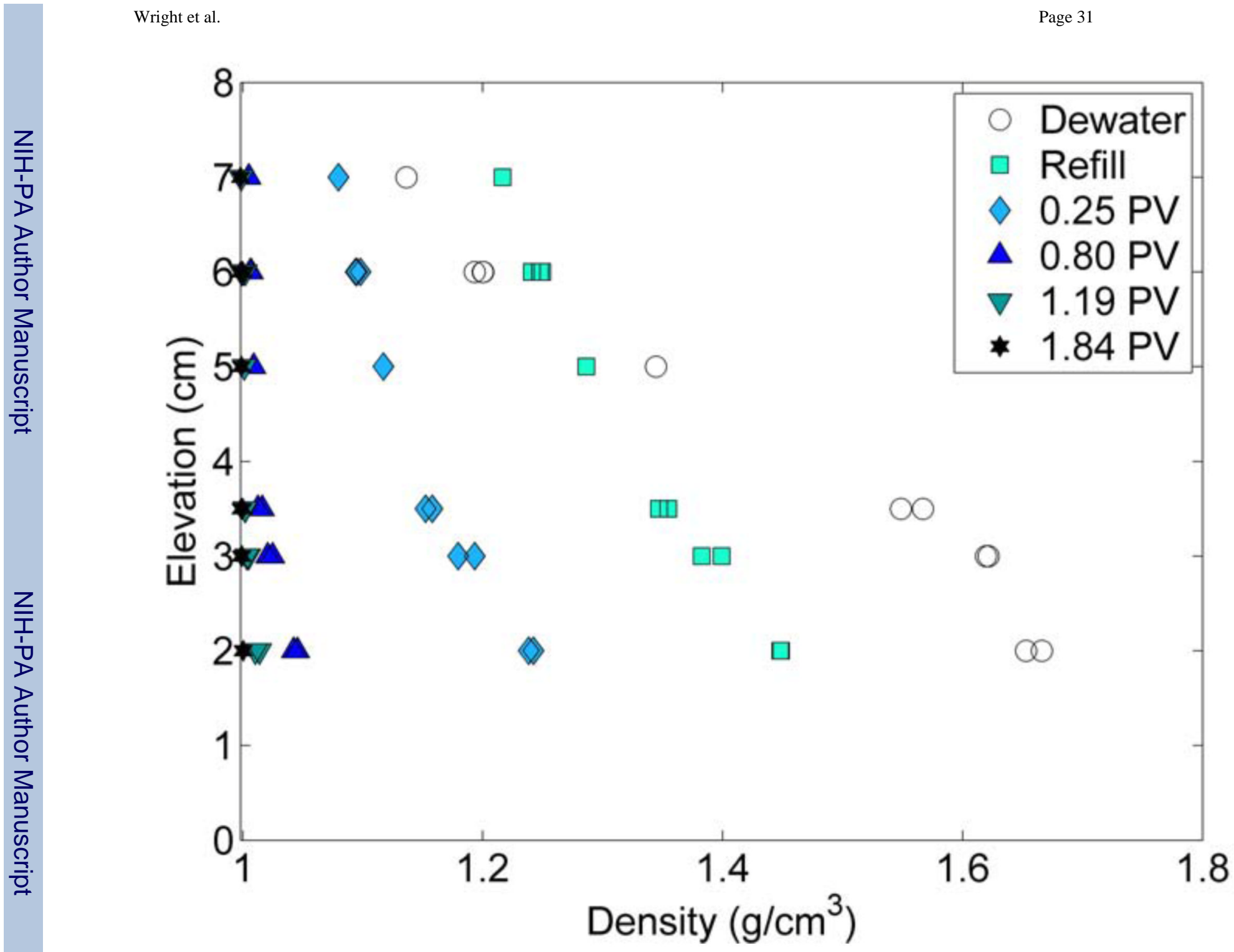

Fig. 7.

Density as a function of elevation during the recovery of the brine barrier for the QS laboratory experiment. 


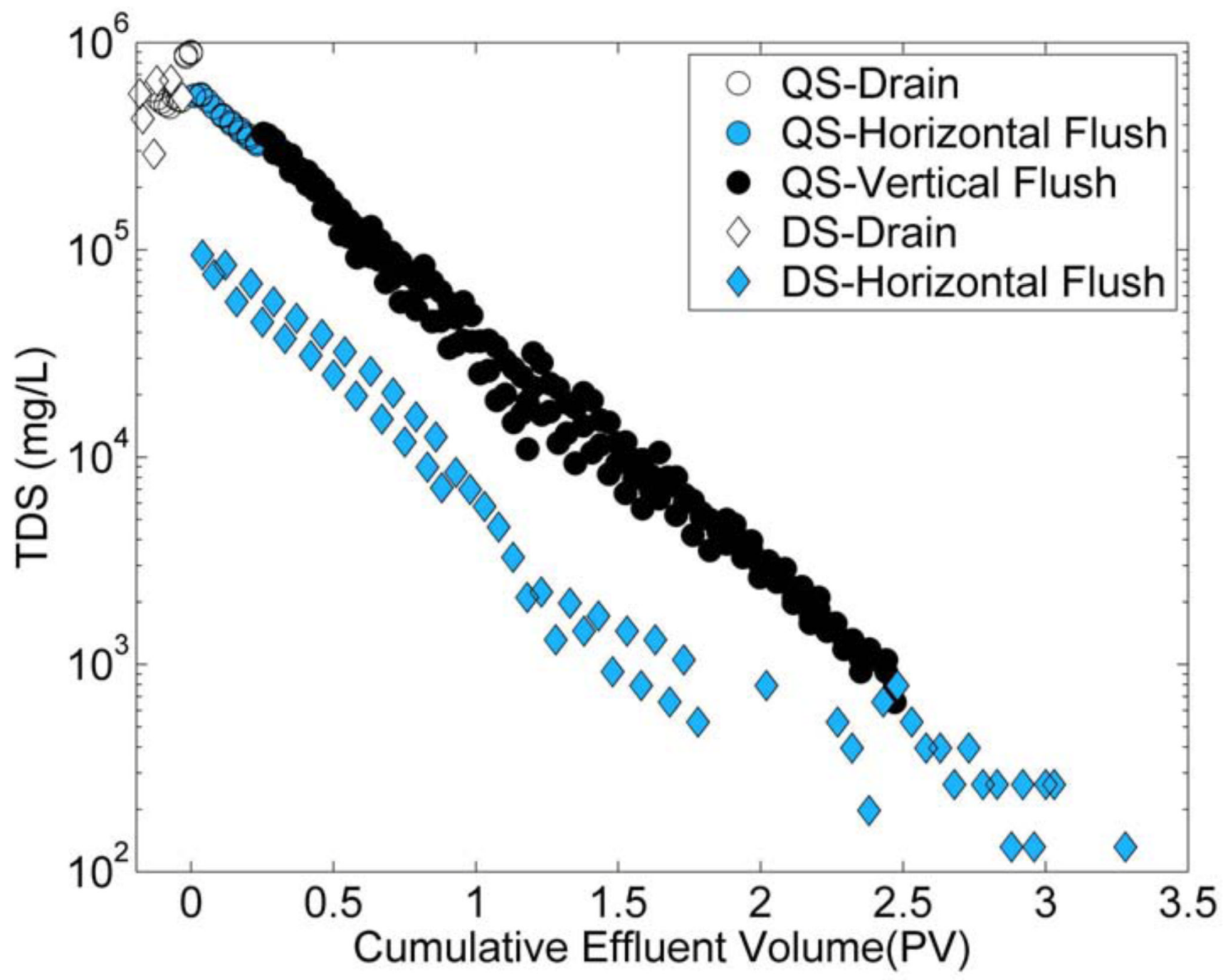

Fig. 8.

Effluent TDS concentration during calcium bromide removal from the laboratory experiments, where $\circ$ represents the QS medium and $\diamond$ represents the DS medium. 


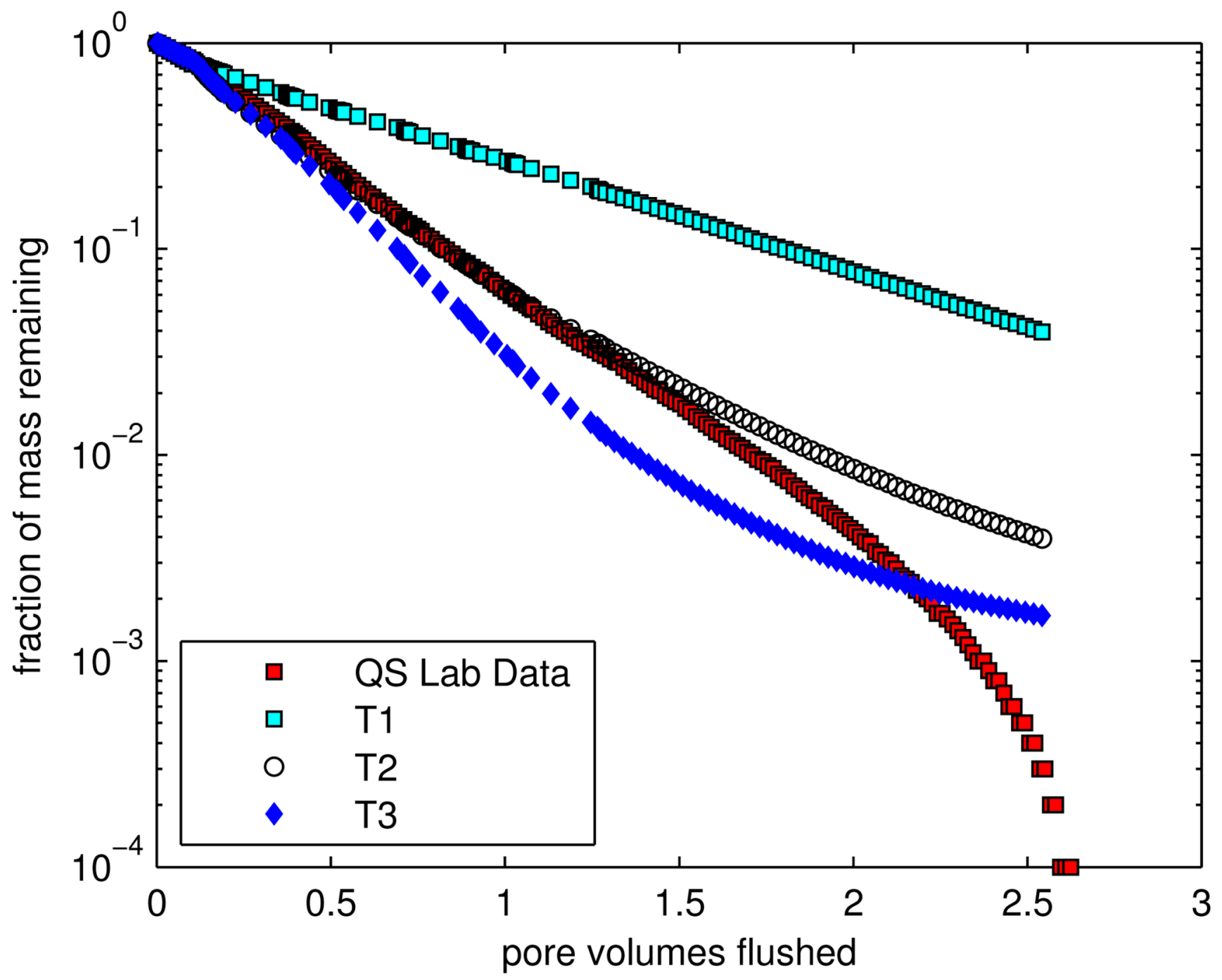

Fig. 9.

Experimental and simulated fraction of calcium bromide remaining in the laboratory experiment with quartz sand medium. 


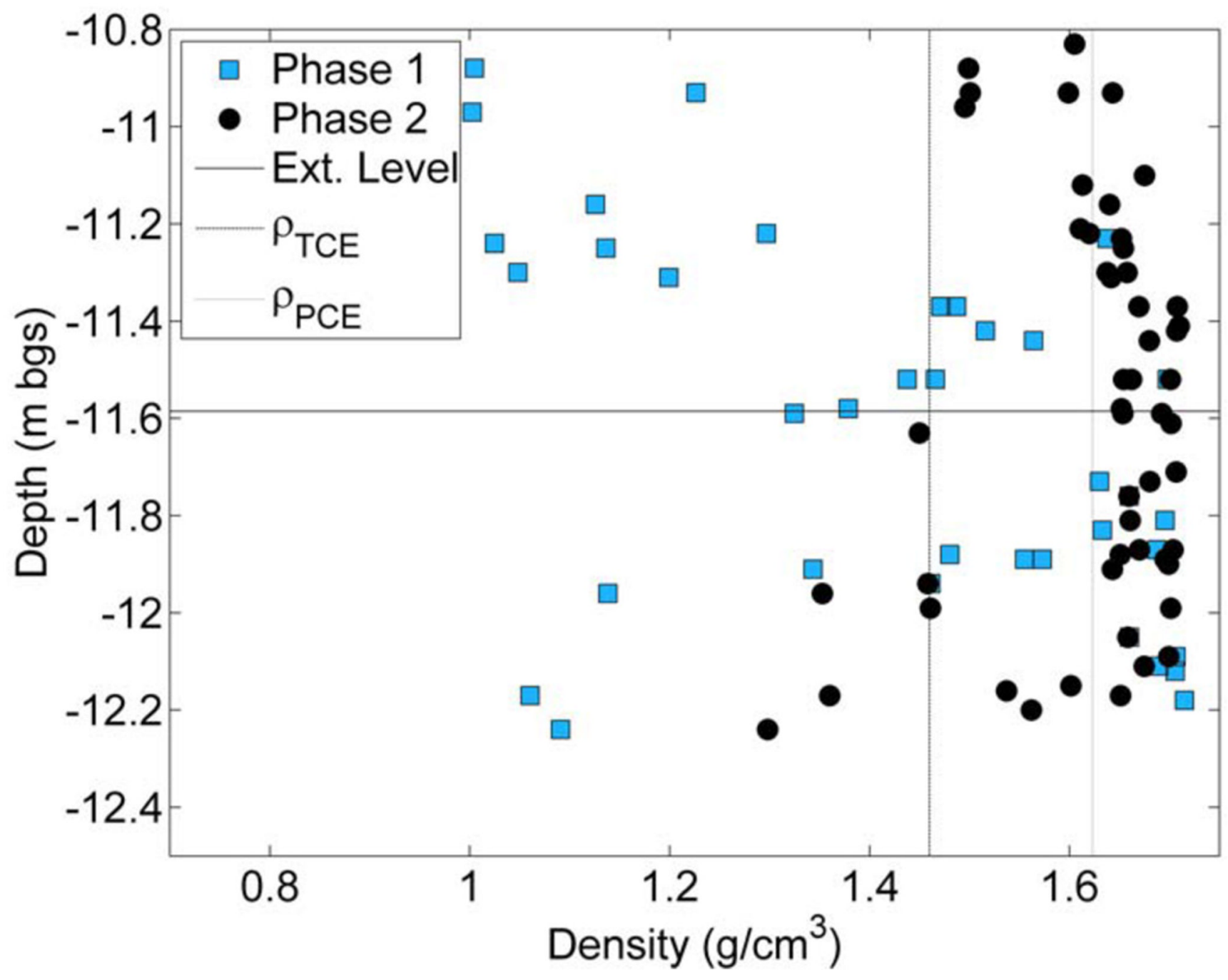

Fig. 10.

In situ densities after Phase 1 and Phase 2 brine additions. The depth of extraction is indicated on the plot as a solid horizontal line. The densities of PCE and TCE are provided as a point of reference. 


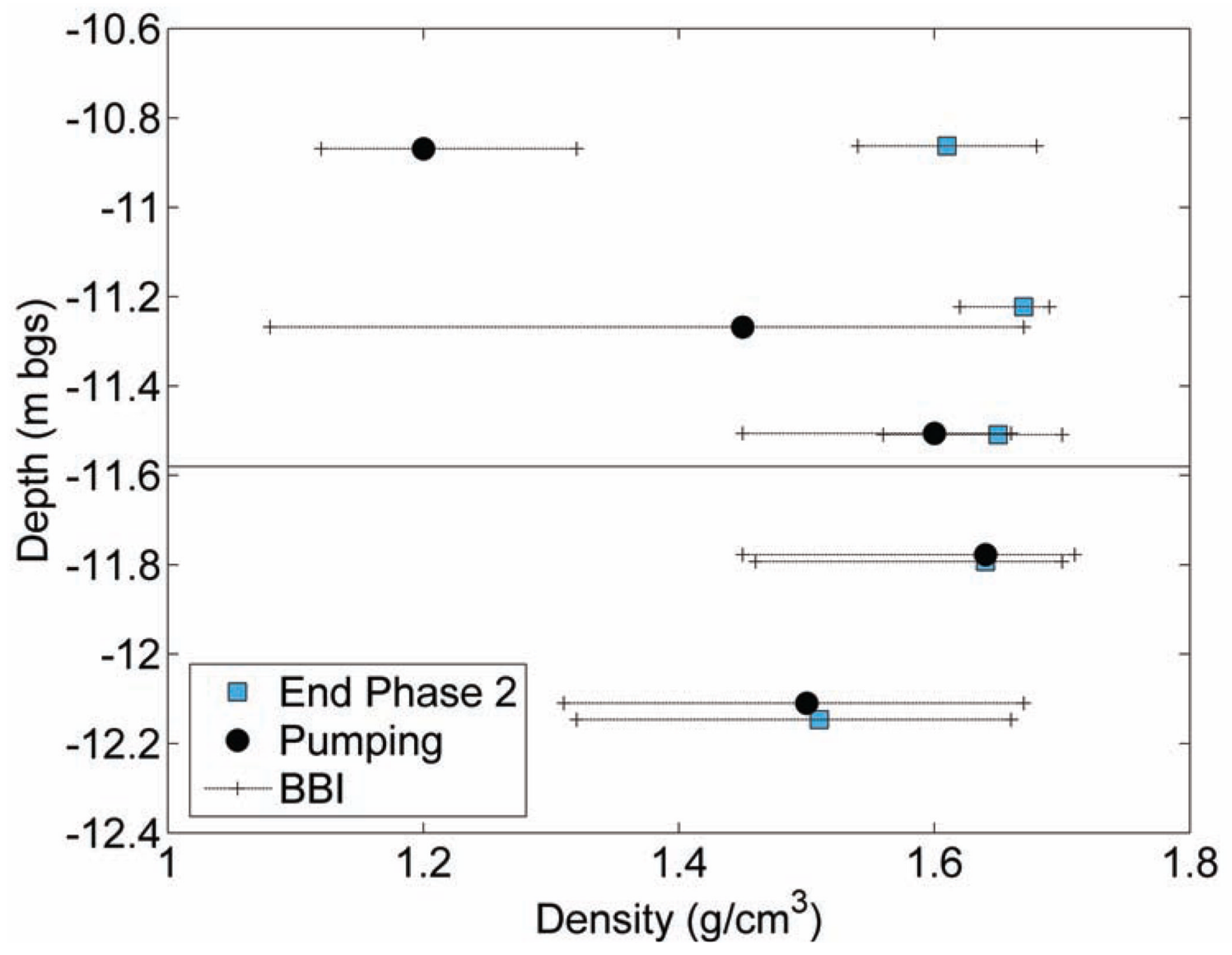

Fig. 11.

Average density as a function of depth during implementation of the BBRT remediation strategy. The solid horizontal line represents the brine barrier interface. 


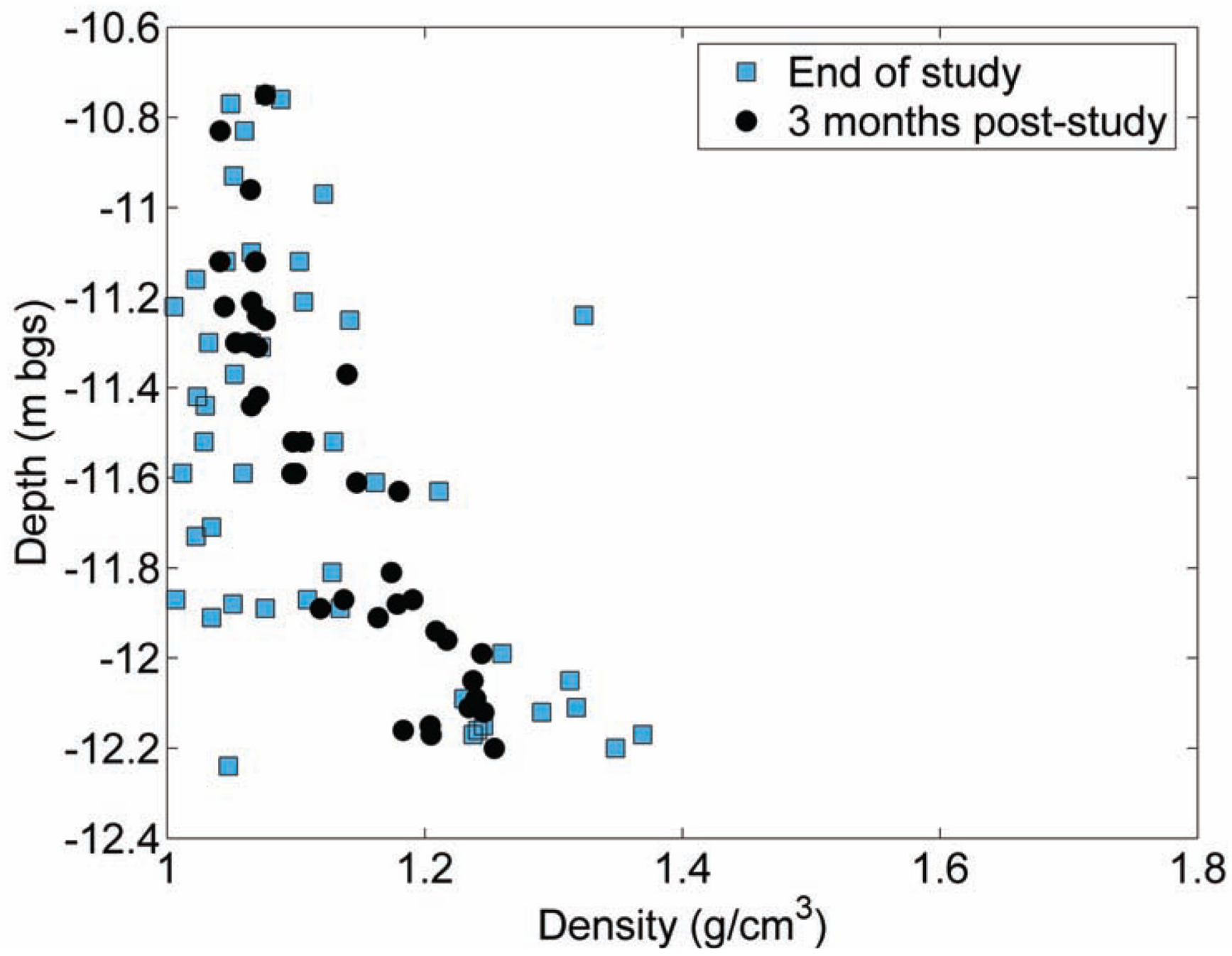

Fig. 12.

Density as a function of depth at the end of the primary study and three months post-study. 


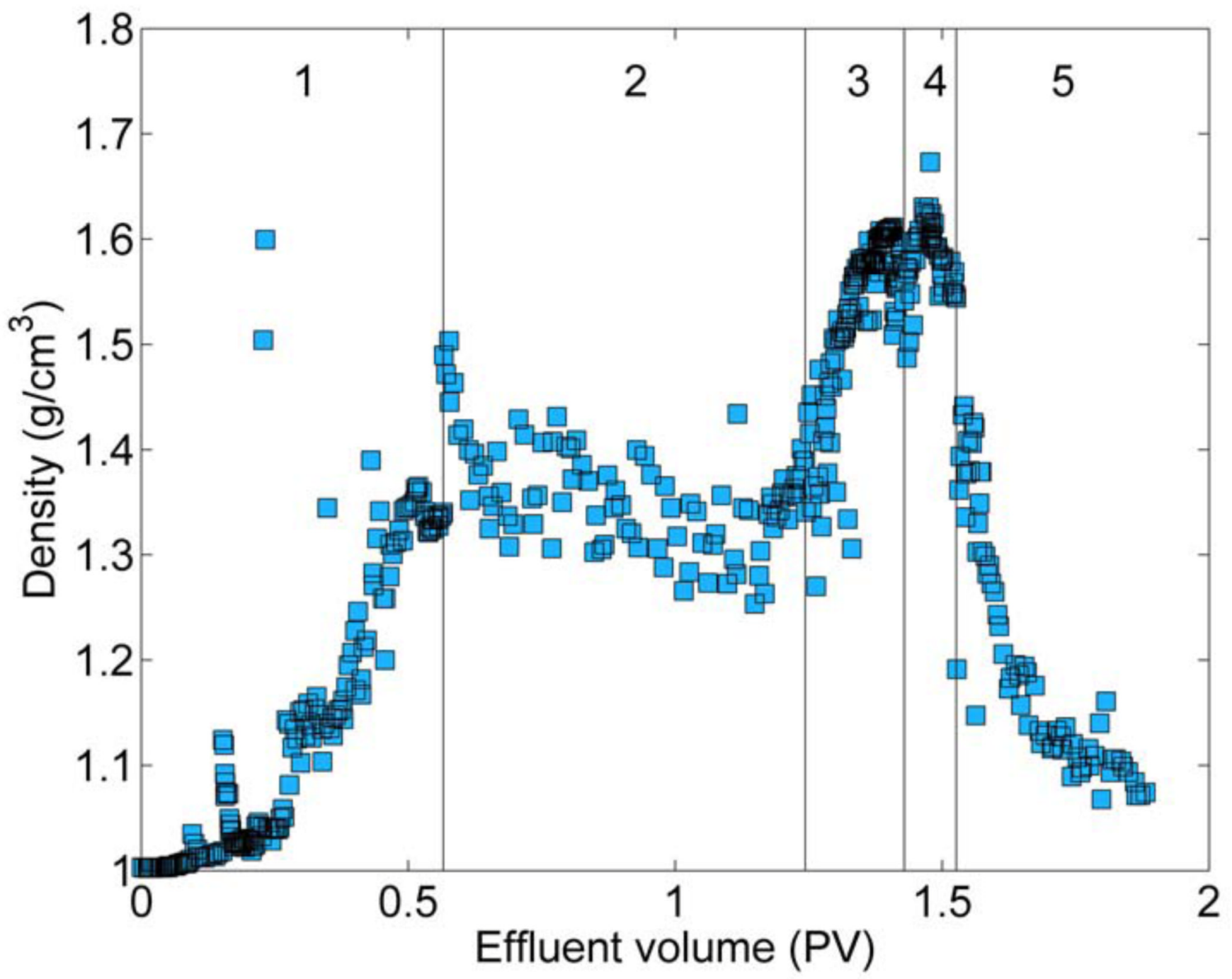

Fig. 13.

Effluent density as a function of effluent volume during (1) brine injection, (2) flushing solution addition, (3) dewatering, (4) bulk brine removal, and (5) brine barrier flushing. 


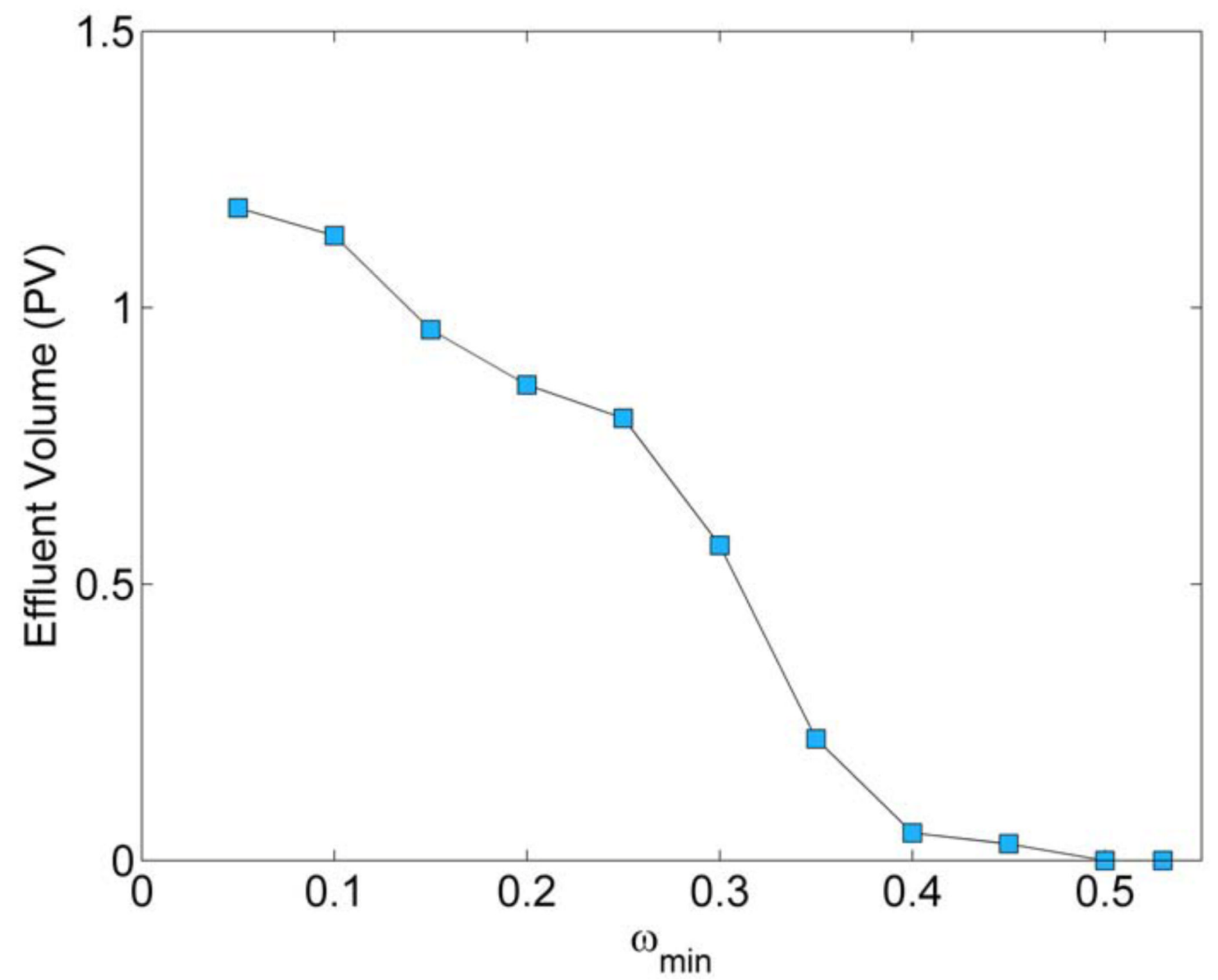

Fig. 14.

The volume of effluent exceeding a minimum mass fraction $\left(\omega_{\min }\right)$. 

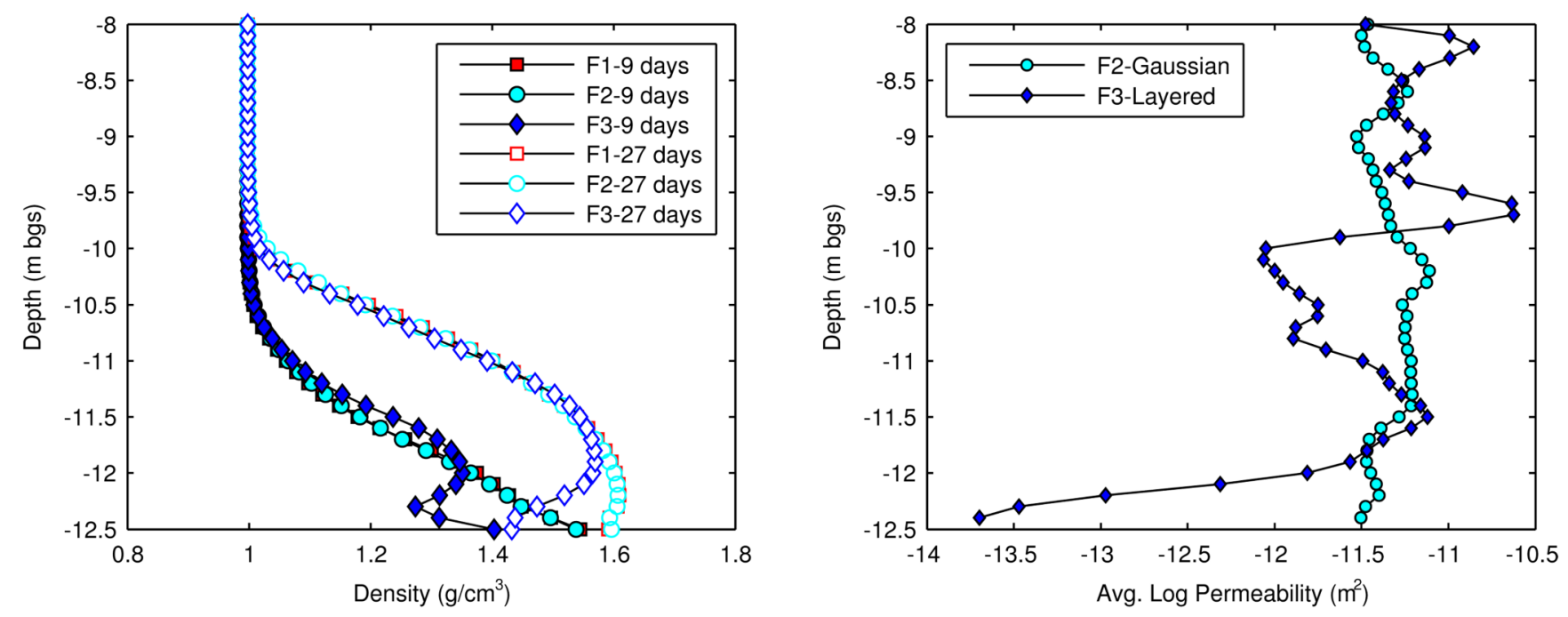

Fig. 15.

(left) Simulated average densities with depth for different permeability fields in the field-scale simulations, where F1 is the homogeneous, F2 is the Gaussian, and F3 is the layered permeability field. (right) Average permeability with depth for the Gaussian and layered permeability fields. 


\section{Table 1}

Porous medium properties.

\begin{tabular}{lcc}
\hline Property & Dover sand (DS) & Quartz sand (QS) \\
\hline $\mathrm{d}_{50}(\mathrm{~mm})$ & 0.47 & 0.30 \\
Uniformity coefficient $\left(\mathrm{d}_{60} / \mathrm{d}_{10}\right)$ & 2.79 & 4.30 \\
Particle density $\left(\mathrm{g} / \mathrm{cm}^{3}\right)$ & 2.63 & 2.66 \\
Porosity & 0.44 & 0.33 \\
Pore Volume & $3.775 \mathrm{~L}$ & $2.604 \mathrm{~L}$ \\
Packing & corr. random field & homogenized \\
\hline
\end{tabular}




\section{Table 2}

Summary of laboratory experiments during brine barrier establishment and maintenance

\begin{tabular}{|lcccc|}
\hline Stage & \multicolumn{2}{c}{ Brine Barrier Establishment } & \multicolumn{2}{c|}{ Pumping and Dewatering } \\
\hline Medium & QS & DS & QS & DS \\
Injection ports & B1-B6 & L1-L4 & B1-B6, L3-L4 & L1-L4 \\
Extraction ports & - & - & E1, L1-L4 & E1-E2, B3-B4, L1-L4 \\
Sample locations & Q1-Q12 & D1-D6 & Q1-Q7 & D1-D6 \\
Injection/extraction (PV) & 0.65 & 0.42 & 0.30 & 0.16 \\
\hline
\end{tabular}


Table 4

SUTRA model parameters for brine simulations of laboratory and field experiments.

\begin{tabular}{lccc}
\hline Model Parameter & Units & Lab Value & Field Value \\
\hline Freshwater density & $\mathrm{g} / \mathrm{cm}^{3}$ & 0.9982 & 0.9982 \\
Freshwater viscosity & $\mathrm{cP}$ & 1.0019 & 1.0019 \\
Brine source mass fraction & $\mathrm{g} / \mathrm{g}$ & 0.53 & 0.53 \\
Brine source density & $\mathrm{g} / \mathrm{cm}^{3}$ & 1.70 & 1.70 \\
Brine source viscosity & $\mathrm{cP}$ & 6.1 & 6.1 \\
Porosity & {$[-]$} & 0.33 & 0.35 \\
Mean intrinsic permeability & $\mathrm{m}^{2}$ & $8.3 \times 10^{-12}$ & $3 \times 10^{-12}$ \\
Longitudinal dispersivity & $\mathrm{m}$ & 0.0048 & 0.48 \\
Transverse dispersivity & $\mathrm{m}$ & 0.0016 & 0.16 \\
Molecular diffusivity & {$\left[\mathrm{m}^{2} / \mathrm{s}\right]$} & $1.22 \times 10^{-9}$ & $1.22 \times 10^{-9}$ \\
$n$ (van Genuchten) & {$[-]$} & 2.0 & 2.0 \\
$\alpha$ (van Genuchten) & {$[-]$} & $5 \times 10^{-5}$ & $5 \times 10^{-5}$ \\
\hline
\end{tabular}




\section{Table 5}

Dispersivity coefficients for laboratory experiment simulations

\begin{tabular}{crr}
\hline Simulation & $\boldsymbol{\alpha}_{\boldsymbol{L}}$ & $\boldsymbol{\alpha}_{\boldsymbol{T}}$ \\
\hline $\mathrm{T} 1$ & $0.048 \mathrm{~m}$ & $0.016 \mathrm{~m}$ \\
$\mathrm{~T} 2$ & $0.0048 \mathrm{~m}$ & $0.0016 \mathrm{~m}$ \\
$\mathrm{~T} 3$ & $0.00048 \mathrm{~m}$ & $0.00016 \mathrm{~m}$ \\
\hline
\end{tabular}




\section{Table 6}

Permeability fields for field-scale simulations.

\begin{tabular}{ccccc}
\hline Simulation & Domain & Variance & $\gamma_{x}$ & $\gamma_{y}$ \\
\hline F1 & Homogeneous & 0 & - & - \\
F2 & Gaussian SRF & 1 & $2.5 \mathrm{~m}$ & $0.5 \mathrm{~m}$ \\
F3 & Layered & 2 & - & $0.5 \mathrm{~m}$ \\
\hline
\end{tabular}

